\title{
Phase Behavior of System Methane + Hydrogen Sulfide
}

\author{
Stefano Langè ${ }^{\mathrm{a}}$, Marco Campestrini ${ }^{\mathrm{b}}$, Paolo Stringari ${ }^{\mathrm{b}, *}$
}

${ }^{a}$ Politecnico di Milano- Dipartimento di Chimica, Materiali e Ingegneria Chimica"Giulio Natta", Piazza Leonardo da Vinci 32, I-20133, Milan, Italy

${ }^{b}$ MINES ParisTech, PSL Research University, CTP - Centre of Thermodynamics of Processes, 35 rue St Honoré 77300 Fontainebleau, France 


\begin{abstract}
An accurate description of the phase behavior of the $\mathrm{CH}_{4}+\mathrm{H}_{2} \mathrm{~S}$ system is given for temperatures from $70 \mathrm{~K}$ to the critical temperature of $\mathrm{H}_{2} \mathrm{~S}$ and pressures up to $250 \mathrm{MPa}$. The study includes the solid phases of $\mathrm{CH}_{4}$ and $\mathrm{H}_{2} \mathrm{~S}$. A global pressure-temperature diagram is presented. The types of temperature-composition and pressure-composition phase diagrams that can be encountered in the studied temperature and pressure ranges have been described. The temperature and pressure ranges where the phase behavior of the system changes have been identified and a representative phase diagram is presented for each range. Phase diagrams have been obtained through the solid-liquidvapor equation of state proposed by Yokozeki. The parameters of the equation of state have been regressed on all the available phase equilibrium data for the considered system.
\end{abstract}

Keywords: Natural gas purification, Methane-hydrogen sulfide mixture, Equation of state, Phase diagram, Solid-liquid-vapor equilibrium 


\section{Introduction}

The global energy demand is expected to increase rapidly over the next twenty years. The rise of the primary energy demand is predicted to be $41 \%$ between 2012 and 2035. ${ }^{1}$ Among fossil fuels consumptions, the natural gas ones are projected to have the most rapid growth trend. ${ }^{1}$

Recent studies have shown that $40 \%$ of the remaining natural gas reserves are sour ${ }^{2}$ and/or with high $\mathrm{CO}_{2}$ content $^{3}(15 \%-80 \%)$. In these low quality gas fields, the hydrogen sulfide content in certain gas reservoirs could be high, even up to about $15 \% .^{4}$

In this scenario, a detailed description of the phase behavior of systems containing methane and hydrogen sulfide is necessary to perform the correct process design of new gas purification technologies $^{5-19}$ that are required to allow the profitable production of commercial-grade gas from low quality natural gas reserves. ${ }^{20-21}$

In the range of temperature and pressure investigated in this work ( $\mathrm{T}$ from $70 \mathrm{~K}$ to the critical temperature of $\mathrm{H}_{2} \mathrm{~S}$ and $\mathrm{P}$ up to $250 \mathrm{MPa}$ ), the system $\mathrm{CH}_{4}(1)+\mathrm{H}_{2} \mathrm{~S}$ (2) can present two liquid phases $\left(\mathrm{L}_{1}\right.$, rich in $\mathrm{CH}_{4}$, and $\mathrm{L}_{2}$, rich in $\left.\mathrm{H}_{2} \mathrm{~S}\right)$ and two solid phases $\left(\mathrm{S}_{1}\right.$, rich in $\mathrm{CH}_{4}$, and $\mathrm{S}_{2}$, rich in $\mathrm{H}_{2} \mathrm{~S}$ ) in addition to the vapor phase (V).

Several authors have studied the methane - hydrogen sulfide system from the experimental point of view. The first literature work presenting experimental values for the methane - hydrogen sulfide mixture was published by Reamer et al. ${ }^{22}$ in 1951 . The authors investigated the critical locus and the vapor-liquid equilibrium of the mixture at $277.59 \mathrm{~K}, 310.93 \mathrm{~K}$ and $344.26 \mathrm{~K}^{22}$

A total of 6 experimental values of $\mathrm{VL}_{2} \mathrm{E}$ were measured by Robinson and coauthors: the correspondent temperatures are $310 \mathrm{~K}$, Robinson and Bailey, ${ }^{23}$ and $277 \mathrm{~K}$, Robinson et al. ${ }^{24}$

A more complete experimental investigation of the phase behavior of the system down to $170 \mathrm{~K}$ was carried out by Kohn and Kurata in $1958 .^{25}$ The different mixture compositions under study leaded the authors inferring the presence of two different solid ${ }_{2}$-liquid-vapor equilibrium loci and a solid $_{2}-$ liquid $_{2}-$ liquid $_{1}$-vapor Quadruple Point (QP). The first $\mathrm{S}_{2} \mathrm{LVE}$ locus has a methane rich liquid phase $\left(\mathrm{S}_{2} \mathrm{~L}_{1} \mathrm{VE}\right)$, the second a hydrogen sulfide rich liquid phase $\left(\mathrm{S}_{2} \mathrm{~L}_{2} \mathrm{VE}\right)$. From the $\mathrm{QP}$, a 
$\mathrm{L}_{2} \mathrm{~L}_{1}$ VEand a $\mathrm{S}_{2} \mathrm{~L}_{2} \mathrm{~L}_{1} \mathrm{E}$ curves originate. The $\mathrm{L}_{2} \mathrm{~L}_{1} \mathrm{VE}$ curve ends to a first Upper Critical EndPoint $\left(\mathrm{UCEP}_{1}\right), \mathrm{L}_{2}\left(\mathrm{~L}_{1}=\mathrm{V}\right) . \mathrm{Kohn}$ and Kurata treated the solid phase $\mathrm{S}_{2}$ as pure $\mathrm{H}_{2} \mathrm{~S}^{25}$

Furthermore, Kohn and Kurata argued the presence of a $\mathrm{L}_{2}=\mathrm{V}$ critical locus, which is continuous with a $\mathrm{L}_{1}=\mathrm{L}_{2}$ critical locus at high pressure. This latter ends to a second Upper Critical EndPoint at high pressure $\left(\mathrm{UCEP}_{2}\right), \mathrm{S}_{2}\left(\mathrm{~L}_{1}=\mathrm{L}_{2}\right)$, where the critical curve meets the $\mathrm{S}_{2} \mathrm{~L}_{1} \mathrm{~L}_{2} \mathrm{E}$ curve. In addition to these points, same authors claimed the presence of a second quadruple point at a temperature close to the triple point temperature of methane, where two solid phases $\left(\mathrm{S}_{1}\right.$ and $\left.\mathrm{S}_{2}\right)$, a $\mathrm{CH}_{4}$-rich liquid phase, and a vapor phase coexist in equilibrium. ${ }^{25}$

The system described by Kohn and Kurata is then of Type - III according to the classification of phase diagrams of Van Konynenburg and Scott, ${ }^{26}$ or $1^{\mathrm{P}} \mathrm{AlnQ}$ according to the one by Bolz et al. ${ }^{27}$ Furthermore, the mixture presents two totally immiscible solid phases $\left(S_{1}\right.$ and $\left.S_{2}\right)$ in the low temperature region.

Cheung and Zander $^{28}$ reported few experimental points for the $\mathrm{S}_{2} \mathrm{~L}_{1} \mathrm{E}$ region, while in 1991 supplementary $\mathrm{VL}_{2} \mathrm{E}$ values were obtained by Yarim-Agaev et al. ${ }^{29}$ for temperatures ranging from $222 \mathrm{~K}$ up to $273 \mathrm{~K}$. More recently, Coquelet et al. ${ }^{30}$ have experimentally investigated the $\mathrm{VL}_{2} \mathrm{E}$ behavior together with the immiscibility gap in the liquid phase at $186.25 \mathrm{~K}$ and $203.4 \mathrm{~K}$, thus proposing the first literature values of $\mathrm{L}_{1} \mathrm{~L}_{2} \mathrm{E}$.

From the modeling point of view, different approaches have been used in the literature to represent the phase behavior of the mixture of interest in this work. Equations of state have been largely used to this scope. Examples are the works by Huron et al., ${ }^{31}$ Adachi et al., ${ }^{32}$ Mohsen-Nia et al., ${ }^{33}$ and Sakoda and Uematsu. ${ }^{34-35}$

Huron et al. ${ }^{31}$ used the Soave-Redlich-Kwong Equation of State (EoS); Adachi et al. ${ }^{32}$ adopted a cubic EoS with four parameters; Mohsen-Nia et al. ${ }^{33}$ made use of a two constant cubic EoS; an EoS in the Helmholtz free energy form was used by Sakoda and Uematsu ${ }^{34-35}$ for representing the phase behavior and thermal properties of the system. Same authors investigated the Pressure-Temperature 
(PT) diagram including only equilibria between fluid phases (namely $\mathrm{VL}_{2} \mathrm{E}, \mathrm{L}_{2} \mathrm{~L}_{1} \mathrm{VE}$ and the critical locus of the system), without any extension to phase equilibria involving solid phases. ${ }^{34-35}$

Privat et al. ${ }^{36}$ used a temperature dependent $k_{i j}$ parameter within the group contribution model PPR78 and compared the calculated values with literature data of equilibria involving fluid phases. Tsivintzelis et al. ${ }^{37}$ studied the methane-hydrogen sulfide system with the CPA EoS considering four different association schemes for $\mathrm{H}_{2} \mathrm{~S}$. As in the works by Sakoda and Uematsu, ${ }^{34-35}$ and Privat et al., ${ }^{36}$ Tsivintzelis et al. ${ }^{37}$ represented only fluid phases.

In 2010, Tang and Gross ${ }^{28}$ have published the first modeling work involving also the apparition of the solid phase at low temperature. The authors used the PCP-SAFT EoS and the PC-SAFT EoS for the fluid phases and a fugacity equation for the solid phase considered as pure $\mathrm{H}_{2} \mathrm{~S}$. Nevertheless, the presented study is limited to temperatures higher than the temperature of the $S_{2} L_{2} L_{1} V$ quadruple point. $^{38}$

In this work the detailed phase behavior of the $\mathrm{CH}_{4}+\mathrm{H}_{2} \mathrm{~S}$ system has been investigated using the analytical equation of state for Solid, Liquid and Vapor phases, SLV EoS. ${ }^{39}$ The phase diagram has been studied for temperatures from $70 \mathrm{~K}$ up to the critical temperature of $\mathrm{H}_{2} \mathrm{~S}$ and for pressures up to $250 \mathrm{MPa}$. The $\mathrm{CH}_{4}+\mathrm{H}_{2} \mathrm{~S}$ phase behavior has been investigated for the first time in a so wide range of temperature and pressure. With respect to the cited literature works on the phase behavior of the $\mathrm{CH}_{4}+\mathrm{H}_{2} \mathrm{~S}$ system, this work adds new information about the phase diagram, especially for the low temperature region and the high pressure region. Isothermal $\mathrm{P}-\mathrm{x}$ diagrams and isobaric $\mathrm{T}-\mathrm{x}$ diagrams are presented for all the P-T regions in which the system changes qualitatively the phase behavior. For a chosen temperature and pressure in the investigated P-T range, the reader can find a $\mathrm{P}-\mathrm{x}$ or $\mathrm{T}-\mathrm{x}$ diagram representative of the behavior of the system. In practice, this work provides a map of the $\mathrm{CH}_{4}+\mathrm{H}_{2} \mathrm{~S}$ phase behavior that can be used for the process design, crystallization risk evaluation, or other purposes that need a reliable representation of the phase behavior of the system. 


\section{Solid Transitions in Pure $\mathrm{CH}_{4}$ and $\mathrm{H}_{2} \mathrm{~S}$}

From the authors' knowledge, the work by Kohn and Kurata ${ }^{25}$ is the first dealing with the solid phases of the methane-hydrogen sulfide system. As stated in the previous section, these authors described the phase diagram of the mixture taking into account two solid phases made of pure $\mathrm{CH}_{4}$ $\left(\mathrm{S}_{1}\right)$ and pure $\mathrm{H}_{2} \mathrm{~S}\left(\mathrm{~S}_{2}\right)$, respectively.

Nevertheless, these components present different phase transitions in the solid phase. The orders and the types of the transitions that occur in the molecular crystals of methane and hydrogen sulfide have been widely discussed in the literature ${ }^{40-43}$, and agreements have been reached about the solidsolid transition temperatures and the related thermodynamic properties.

According to Colwell et al. ${ }^{40}$ methane has two possible crystal lattices $(\alpha$ and $\beta$ ) resulting in a solid $_{\alpha}$-solid ${ }_{\beta}$ transition and a related $\operatorname{solid}_{\alpha}$-solid ${ }_{\beta}$-vapor triple point located at $20.5 \mathrm{~K}$ and vapor pressure $(\mathrm{P} \approx 0)$. Crystal lattices $\alpha$ and $\beta$ have been stated to have a face-centered cubic (fcc) structure, and the solid transition involves uniquely changes in the degree of orientational order of the fcc structure. ${ }^{40}$ In 1957 , Stevenson ${ }^{41}$ used a strong cylindrical container for measuring pressurevolume isotherms and found two additional solid phases $(\gamma$ and $\delta$ ). As a consequence, the pressuretemperature diagram of pure methane presents other three solid-solid transition boundaries ( $\beta-\gamma, \alpha-$ $\gamma$, and $\gamma-\delta$ ) and a solid $\alpha$-solid ${ }_{\beta}-$ solid $_{\gamma}$ triple point located at about $32 \mathrm{~K}$ and $260 \mathrm{MPa}$. In the low temperature region, the $\beta-\gamma$ and $\gamma-\delta$ phase equilibrium curves do not match any other phase transition curve, and they go toward absolute zero at about $90 \mathrm{MPa}$ and $210 \mathrm{MPa}$, respectively. Furthermore, the $\gamma-\delta$ boundary extends in the high pressure region remaining always located at temperatures lower than $35 \mathrm{~K}^{41}$

In1936, Giauque and Blue ${ }^{42}$ carried out experimental measurements for pure $\mathrm{H}_{2} \mathrm{~S}$ by means of a calorimetric apparatus and observed two solid-solid transitions in addition to the freezing transition. Authors observed a region of considerable energy absorption at $126 \mathrm{~K}$ and a sharp transition at 103.5 K. The former solid-solid transition was explained as an orientational ordering with respect to the rotational vibrations of the hydrogen atoms, whereas a drop in the dielectric constant was 
associated to the latter. Giauque and Blue ${ }^{42}$ underlined then the presence of three fcc structures $(\alpha$, $\beta$, and $\gamma$ ) for solid $\mathrm{H}_{2} \mathrm{~S}$, and suggested three triple points ( solid $_{\alpha}$-liquid-vapor, solid $_{\alpha}$-solid ${ }_{\beta}$-vapor, and solid $_{\beta}$-solid ${ }_{\gamma}$-vapor) at vapor pressure $(\mathrm{P} \approx 0)$. Successively, Stevenson ${ }^{43}$ showed the presence of other two solid phases ( $\delta$ and $\kappa$ ) of $\mathrm{H}_{2} \mathrm{~S}$ in the high pressure region by a volume discontinuity method. The slopes of the related solid-solid boundaries are such as to originate four solid-solidsolid triple points between $110 \mathrm{~K}$ and $160 \mathrm{~K}$, and $400 \mathrm{MPa}$ and $900 \mathrm{MPa}{ }^{43}$

All the solid-solid-solid triple points of pure methane and hydrogen sulfide occur at pressures higher than $250 \mathrm{MPa},{ }^{40-43}$ then this limit has been considered for the application of the thermodynamic model used in this work. With respect to the low pressure region and the solidsolid-vapor triple points, only pure $\mathrm{H}_{2} \mathrm{~S}$ presents more than one solid phase in the range of temperature chosen in this work $(70-373 \mathrm{~K})$. Nevertheless, these solid-solid transitions do not involve a meaningful change in the solid-fluid equilibria of the mixture seeing that the solid phase $\mathrm{S}_{2}$ is always made of fcc crystals of pure $\mathrm{H}_{2} \mathrm{~S}$. This aspect has been pointed out in the last section of this work, where the presence of two additional solid phases for pure $\mathrm{H}_{2} \mathrm{~S}$ have been qualitatively taken into account in a temperature-composition diagram and compared with the case of considering a single solid phase. 


\section{Thermodynamic Model}

The pressure-explicit equation of state proposed by Yokozeki in 2003is presented in Eq. 1. ${ }^{39}$

$$
P(T, v)=\frac{R T}{v-b} \frac{v-d}{v-c}-\frac{a}{v^{2}+q b v+r b^{2}}
$$

In Eq. $1, P$ is the pressure, $R$ is the gas constant, $T$ is the temperature, $v$ is the molar volume, $a$ keeps into account the attractive forces among molecules, $c$ is the liquid covolume, $b$ is the solid covolume, $d$ is molar volume for which the repulsive term in Eq. 1 is null, $q$ and $r$ are parameters of the attractive term. The van der Waals attractive term $(q, r=0)$ has been considered in this work.

According to Yokozeki, parameters $a$ and $b$ in Eq. 1 are temperature dependent functions whose functional forms are given in Eqs. 2 and 3:

$$
\begin{aligned}
& a(T)=\frac{\left(R T_{c}\right)^{2}}{P_{c}}\left[a_{0}+a_{1} T_{r} \exp \left(-a_{2} T_{r}^{n}\right)\right] \\
& b(T)=v_{c}\left\lfloor b_{0}+b_{1} \exp \left(-b_{2} T_{r}^{m}\right)\right\rfloor
\end{aligned}
$$

where $T_{r}=T / T_{c}$ is the reduced temperature, $a_{0}, a_{1}, a_{2}, n, b_{0}, b_{1}, b_{2}$, and $m$ are parameters, $R$ is the gas constant, and $T_{c}, P_{c}$, and $v_{c}$ are temperature, pressure, and volume at the critical point.

The application of Eqs. 1-3 for the representation of the phase equilibrium behavior of a pure component requires the previous evaluation of 11 parameters (the critical volume $v_{c}$ or equivalently the critical compressibility coefficient $Z_{c}, a_{0}, a_{1}, a_{2}, n, b_{0}, b_{1}, b_{2}, m, c$, and $d$ ). The procedure deeply illustrated by Stringari et al. ${ }^{44}$ has been used to this scope.

This procedure is based on the analytical representation of the critical and triple points of a pure component, and on the minimization of an objective function based on the isofugacity conditions along the saturation, sublimation, and melting curves. The fugacities of the coexisting phases are evaluated at the experimental conditions (temperature and pressure) of equilibrium.

For $\mathrm{CH}_{4}$, pseudo-experimental temperature-pressure couples for vapor-liquid, solid-vapor, and solid-liquid equilibria have been generated from accurate auxiliary equations ${ }^{45}$ considering these values as true equilibrium values. Therefore, it has been considered that comparing the model with 
the values obtained from the auxiliary equations (referred to as auxiliary values) is equivalent to compare the model to experimental data, seeing that these auxiliary equations are precise correlations of the available experimental data.

For $\mathrm{H}_{2} \mathrm{~S}$, only the auxiliary equation for the vapor-liquid equilibrium is available ${ }^{45}$. Experimental values of sublimation have been proposed by Stevenson, ${ }^{43}$ and Clark et al., ${ }^{46}$ while temperaturepressure couples of solid-liquid equilibrium have been generated by means of Eq. 4 .

$$
P^{S L E}=P_{t}+\frac{\Delta H^{S L E}}{\Delta v^{S L E}}\left(1+\frac{T_{t}}{T}\right)
$$

Eq. 4 has been obtained from the expression relating the solid and the liquid fugacities of a pure component, also known as "classic approach". ${ }^{47}$ In Eq. $4, P_{t}$ is the triple point pressure, $T_{t}$ is the triple point temperature, $\Delta H^{S L E}=H_{L^{-}} H_{S}$ and $\Delta v^{S L E}=v_{L^{-}} v_{S}$ are latent heat of fusion and the volume change upon melting at the triple point, whose values are $2.377 \mathrm{~kJ} / \mathrm{mol},{ }^{48}$ and $3.892 \mathrm{~cm}^{3} / \mathrm{mol}^{49}$ respectively.

The references of VLE, SLE, and SVE data needed for the regression of parameters of the pure components are summarized in Table 1.

Table 1. Summary of the data sources used for SVE, SLE, and VLE of pure methane and hydrogen sulfide.

\begin{tabular}{|c|c|c|c|}
\hline Substance & $V L E$ & SLE & SVE \\
\hline $\begin{array}{l}\mathrm{CH}_{4} \\
\mathrm{H}_{2} \mathrm{~S}\end{array}$ & $\begin{array}{l}\text { auxiliary values }^{45} \\
\text { auxiliary values }\end{array}$ & $\begin{array}{c}\text { auxiliary values } \\
\text { generated values, Eq. } 4\end{array}$ & $\begin{array}{c}\text { auxiliary values }^{45} \\
\text { experimental values }\end{array}$ \\
\hline
\end{tabular}

For sake of simplicity, the term data has been henceforth used to group all the kind of values: auxiliary values obtained from auxiliary equations, ${ }^{45}$ experimental values of $\mathrm{SVE}$ for $\mathrm{H}_{2} \mathrm{~S},{ }^{43,46}$ and SLE values calculated by Eq. 4 for $\mathrm{H}_{2} \mathrm{~S},{ }^{47}$.

Values of pressure and temperature at critical and triple points for methane and hydrogen sulfide are presented in Table $2 .^{45}$ 
Table 2. Temperature and pressure of triple and critical points of methane and hydrogen sulfide. ${ }^{45}$

\begin{tabular}{ccccc}
\hline Substance & $P_{t} / \mathrm{kPa}$ & $T_{t} / K$ & $P_{c} / M P a$ & $T_{c} / K$ \\
\hline $\mathrm{CH}_{4}$ & 11.697 & 90.694 & 4.5992 & 190.56 \\
$\mathrm{H}_{2} \mathrm{~S}$ & 22.3 & 187.7 & 9 & 373.1 \\
\hline
\end{tabular}

For each substance, the P-T range used for the regression of the parameters within the SLV EoS extends from a minimum on the sublimation branch to a maximum on the melting branch. These values are presented in Table 3.

Table 3. Temperature and pressure ranges for the regression of the parameters for methane and hydrogen sulfide.

\begin{tabular}{cccllc}
\hline \multirow{2}{*}{ Substance } & \multicolumn{3}{c}{$S V E$} & & \multicolumn{2}{c}{$S L E$} \\
\hline$n_{\text {min }} / K$ & $P_{\min } / \mathrm{kPa}$ & & & $T_{\max } / K$ & $P_{\max } / M P a$ \\
$\mathrm{CH}_{4}$ & 60 & 0.0164 & & 200 & 594 \\
$\mathrm{H}_{2} \mathrm{~S}$ & 130 & 0.0417 & & 400 & 2741 \\
\hline
\end{tabular}

Regressed parameters are $Z_{c}, a_{0}, a_{1}, a_{2}, n, b_{0}, b_{1}, b_{2}, m, c$, and $d$ for $\mathrm{CH}_{4}$ and $\mathrm{H}_{2} \mathrm{~S}$ are reported in

Table 4. Values for $\mathrm{CH}_{4}$ are the same presented by Stringari et al., ${ }^{44}$ and here reported for the reader convenience.

Table 4. Parameters of Eqs. 1-3 for methane and hydrogen sulfide.

\begin{tabular}{cccccccccccc}
\hline Substance & $\begin{array}{c}Z_{c} \\
\left(\mathrm{x} 10^{2}\right)\end{array}$ & $\begin{array}{c}a_{0} \\
\left(\mathrm{x} 10^{2}\right)\end{array}$ & $a_{1}$ & $a_{2}$ & $n$ & $b_{0}$ & $b_{1}$ & $b_{2}$ & $m$ & $\begin{array}{c}c \\
\left(\mathrm{x} 10^{2}\right)\end{array}$ & $\begin{array}{c}d \\
\left(\mathrm{x} 10^{2}\right)\end{array}$ \\
\hline $\mathrm{CH}_{4}$ & 37.50400 & 3.903 & 21.983 & 4.051 & 0.381 & 0.335 & -0.334 & 4.201 & 0.682 & 4.468 & 4.422 \\
\hline $\mathrm{H}_{2} \mathrm{~S}$ & 37.50023 & 0.998 & 11.043 & 3.289 & 0.503 & 0.334 & -0.236 & 5.160 & 1.370 & 4.430 & 4.426 \\
\hline
\end{tabular}

The comparison of the phase equilibrium values calculated with Eq. 1 and data is presented in Table 5 in terms of Absolute Average Deviation, Bias, and Maximum Absolute Deviation. Table 5 represents the deviations obtained calculating the equilibrium pressure at fixed temperature; for each kind of equilibrium, $\mathrm{N}$ is the number of data used for the comparison. Values for $\mathrm{CH}_{4}$ are the same presented by Stringari et al. ${ }^{44}$ 
Table 5. Summary of the statistical errors in calculating equilibrium pressures at fixed temperatures for $\mathrm{CH}_{4}$ and $\mathrm{H}_{2} \mathrm{~S}$.

Errors are evaluated with respect to the auxiliary values of VLE, SLE, SVE of $\mathrm{CH}_{4}$ and of VLE of $\mathrm{H}_{2} \mathrm{~S}$, to the experimental values of SVE of $\mathrm{H}_{2} \mathrm{~S}$, and to the values generated from Eq. 4 for SLE of $\mathrm{H}_{2} \mathrm{~S}$.

\begin{tabular}{|c|c|c|c|c|c|c|c|c|c|c|c|c|}
\hline \multirow[b]{2}{*}{ Substance } & \multicolumn{4}{|c|}{$V L E$} & \multicolumn{4}{|c|}{$S V E$} & \multicolumn{4}{|c|}{$S L E$} \\
\hline & $\begin{array}{c}A A D \\
\%\end{array}$ & $\begin{array}{c}\text { Bias } \\
\%\end{array}$ & $\begin{array}{c}M A D \\
\%\end{array}$ & $N$ & $\begin{array}{c}A A D \\
\%\end{array}$ & $\begin{array}{c}\text { Bias } \\
\%\end{array}$ & $\begin{array}{c}M A D \\
\%\end{array}$ & $N$ & $\begin{array}{c}A A D \\
\%\end{array}$ & $\begin{array}{c}\text { Bias } \\
\%\end{array}$ & $\begin{array}{c}M A D \\
\%\end{array}$ & $N$ \\
\hline $\mathrm{CH}_{4}$ & 0.11 & -0.07 & 0.26 & 131 & 0.03 & 0.01 & 0.06 & 32 & 0.26 & 0.00 & 1.37 & 141 \\
\hline $\mathrm{H}_{2} \mathrm{~S}$ & 0.19 & 0.85 & 4.08 & 118 & 4.08 & 1.99 & 12.38 & 18 & 8.08 & 7.20 & 13.32 & 215 \\
\hline
\end{tabular}

According to Table 5, the SLV EoS agrees well with the auxiliary values ${ }^{45}$ of melting, saturation, and sublimation obtained for $\mathrm{CH}_{4}$. Considering all the kind of equilibrium, the AAD is always lower than $0.3 \%$, the Bias is close to zero, and the highest MAD of about $1.4 \%$ is obtained for the SLE.

Similar results are related to the comparison between the SLV EoS and the auxiliary values ${ }^{45}$ of saturation of $\mathrm{H}_{2} \mathrm{~S}$; the AAD is $0.19 \%$, the Bias lower than $1 \%$, the MAD is about $4 \%$.

Higher deviations are obtained for the quantitative comparison between calculated and experimental pressures of SVE and SLE of $\mathrm{H}_{2} \mathrm{~S}$. With respect to the SVE, the highest deviation (12.38\%) occurs at $130 \mathrm{~K}$ where the experimental pressure is lower than $5 \times 10^{-5} \mathrm{MPa}$. For the SLE, the AAD, Bias and MAD are about $8 \%, 7 \%$, and $13 \%$, respectively. It should be remembered that the pressure of melting have been calculated by means of Eq. 4, which is a simple approximation of the solid-liquid equilibrium.

Pressure-temperature equilibrium behaviors obtained with the SLV EoS are represented in Figures 1-2 for $\mathrm{CH}_{4}$ and $\mathrm{H}_{2} \mathrm{~S}$, respectively; empty symbols are selected data of VLE, SLE, and VLE. 


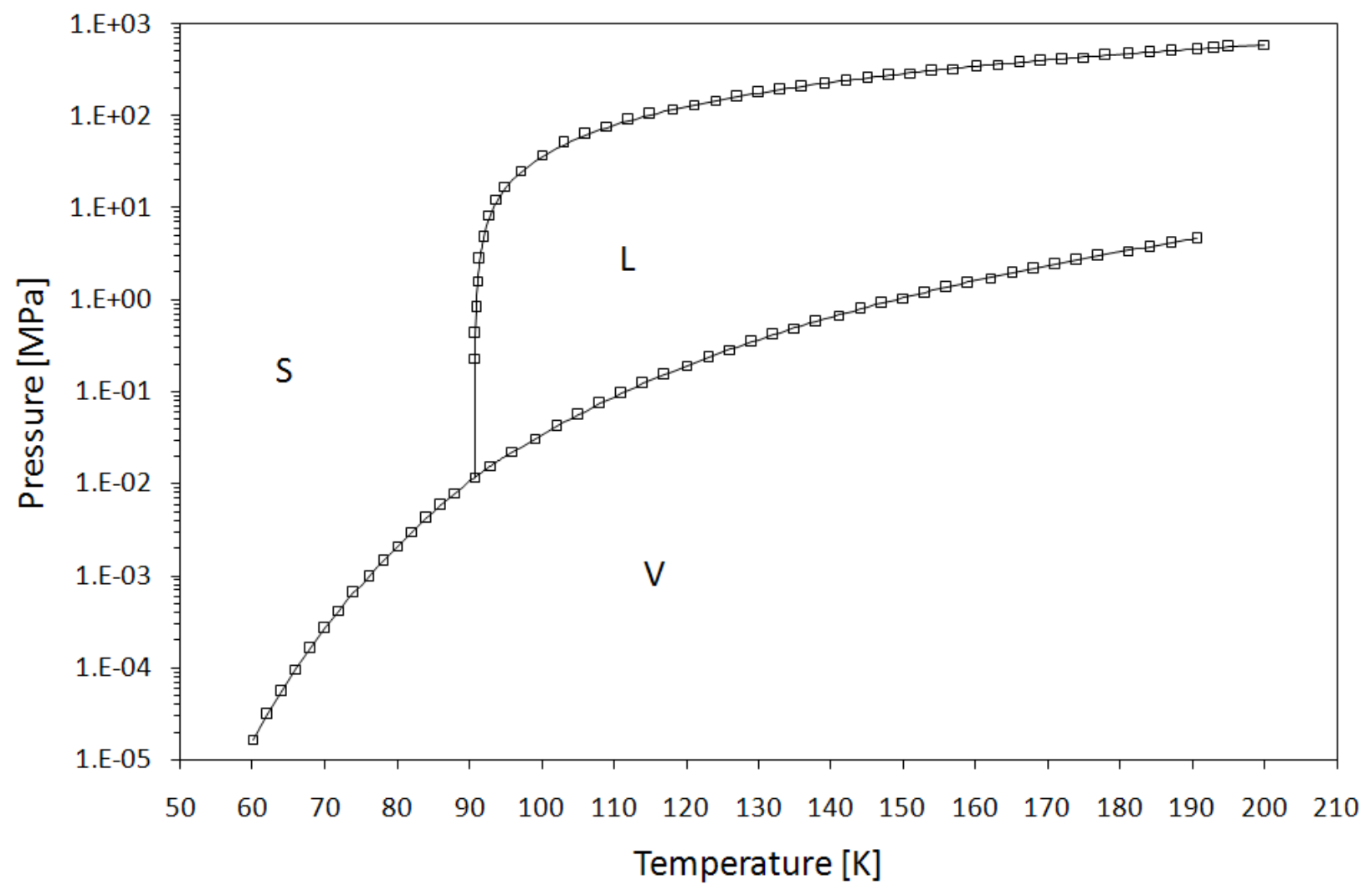

Figure 1. Pressure-temperature phase diagram of $\mathrm{CH}_{4}$.

—: SLV EoS; 口: auxiliary values ${ }^{45}$ for SVE, SLE, and VLE.

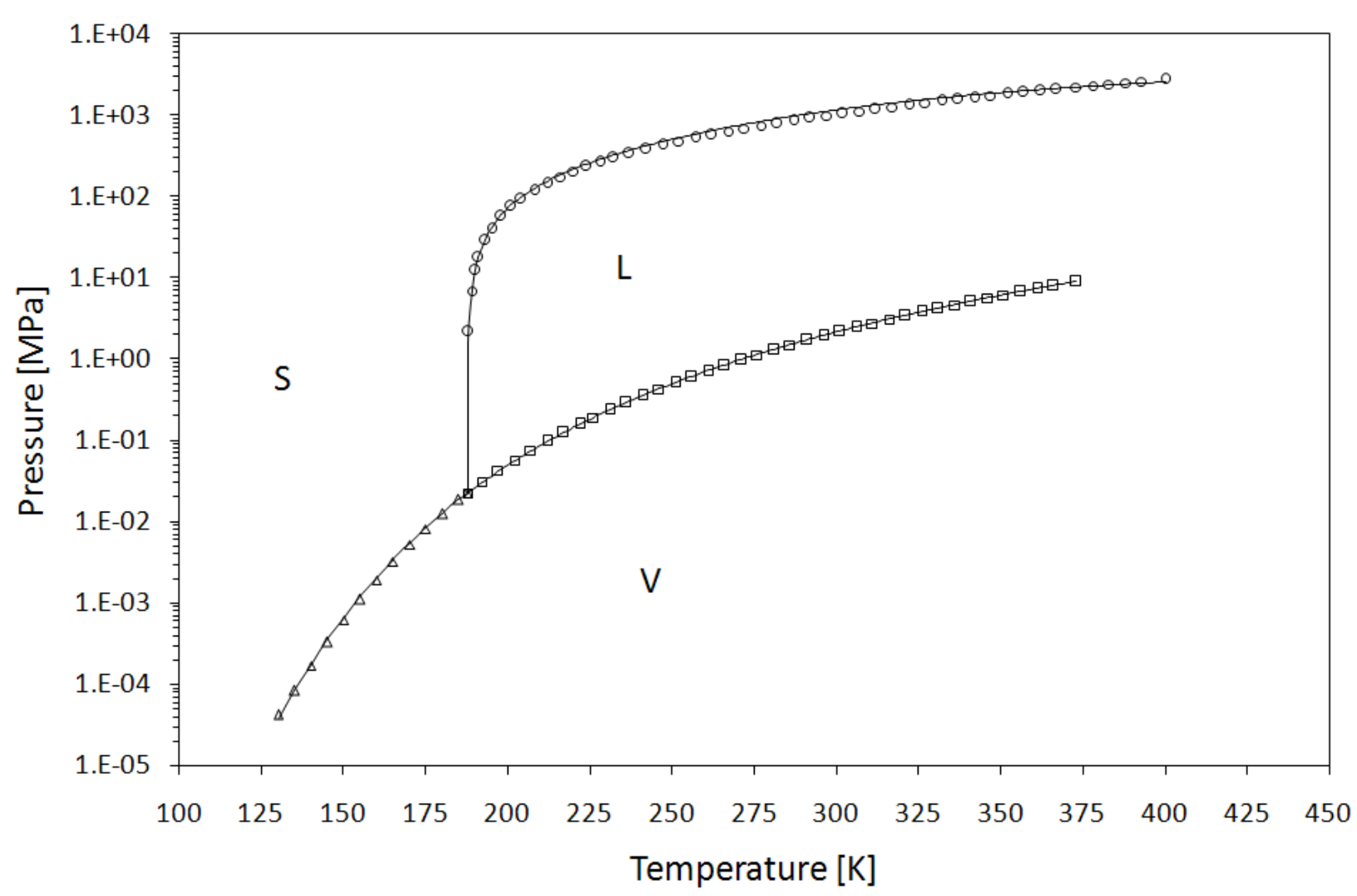

Figure 2. Pressure-temperature phase diagram of $\mathrm{H}_{2} \mathrm{~S}$.

—: SLV EoS; $\square$ : VLE auxiliary values ${ }^{45}$; ○: SLE generated values, Eq. 4; $\Delta$ : SVE experimental values, ${ }^{43,46}$. 
Extension of Eq. 1 to the binary mixture has been considered using the mixing rules proposed by Yokozeki $^{39}$, Eqs. 5-8. The consistency test for the adopted mixing rules has been presented in Ref. 44.

$$
\begin{aligned}
& a=\sum_{i, j=1}^{N C} \sqrt{a_{i} a_{j}}\left(1-k_{i j}\right) x_{i} x_{j} \\
& b=\sum_{i=1}^{N C} b_{i} x_{i} \\
& c=\sum_{i=1}^{N C} c_{i} x_{i} \\
& d=\sum_{i=1}^{N C} d_{i} x_{i}
\end{aligned}
$$

The binary interaction parameter $k_{i j}$ has been regressed by minimization of an objective function defined as the sum of the absolute difference between the calculated and experimental methane compositions, averaged with respect to the total number $N$ of $\mathrm{VL}_{2} \mathrm{E}, \mathrm{L}_{2} \mathrm{~L}_{1} \mathrm{E}$ and $\mathrm{S}_{2} \mathrm{~L}_{1} \mathrm{E}$ data, Eq. 9 .

$$
f o b=\left[\frac{1}{N} \sum_{i=1}^{N}\left|x_{C_{4}}^{\text {calc }}-x_{C_{4}}^{\exp }\right|\right]
$$

In Eq. 9, each calculated composition of methane refers to the equilibrium composition at $\mathrm{VL}_{2} \mathrm{E}$ or $\mathrm{L}_{2} \mathrm{~L}_{1} \mathrm{E}$ obtained by the model by means of a PT flash calculation at imposed experimental temperature and pressure.

In spite of the complex phase equilibrium behavior, a not temperature dependent value for $k_{i j}\left(k_{i j}=\right.$ 0.058) has been found to allow the complete description of the methane-hydrogen sulfide system from $70 \mathrm{~K}$ up to the critical temperature of $\mathrm{H}_{2} \mathrm{~S}$.

Section 4 presents the comparisons between experimental values of equilibrium and the SLV EoS, while Section 5 illustrates the complete phase diagram of the binary mixture in the temperature and pressure ranges of this work.

As it is possible to observe in the figures presented in the following sections, the solid phases $S_{2}$ and $\mathrm{S}_{1}$ calculated by the model are not always pure phases. This discrepancy with what is expected 
according to the literature depends heavily on the functional form of Eqs. 5-8. Because the mixing rules used for the volumetric parameter $b, c$, and $d$ are of the type developed for the fluid phase, it follows that the solid phase is treated as a liquid-like phase, which entails the solubility in the solid phase. The fact that the solid phases are not constituted by a pure component does not affect the quality of the representation of the temperature-pressure-composition data of the fluid phases in equilibrium with the solid. 


\section{Model Validation}

This section has the scope to assess the accuracy and reliability of the developed SLV EoS in representing the existing phase equilibrium data. Once the SLV EoS validated, it will be used in Section 5 for predicting the phase equilibrium behavior of the $\mathrm{CH}_{4}+\mathrm{H}_{2} \mathrm{~S}$ system in the considered range of temperature and pressure.

The quantitative comparison between the values calculated by means of Eq. 1, with the mixing rules of Eqs. 5-8, and the experimental values proposed in the literature is illustrated in Table 6.

The first part of Table 6 presents the comparison between calculated and experimental values of $\mathrm{VL}_{2} \mathrm{E}, \mathrm{L}_{1} \mathrm{~L}_{2} \mathrm{E}$, and $\mathrm{S}_{2} \mathrm{~L}_{1} \mathrm{E}$; errors are in terms of the compositions of methane in the liquid and the vapor phase, obtained by means of a PT flash calculation at imposed experimental temperature and pressure.

The second part of Table 6 portrays the comparison with respect to the experimental values of temperature and pressure related to the three-phase equilibria $\mathrm{S}_{2} \mathrm{~L}_{1} \mathrm{VE}, \mathrm{S}_{2} \mathrm{~L}_{2} \mathrm{VE}, \mathrm{L}_{2} \mathrm{~L}_{1} \mathrm{VE}$, and $\mathrm{S}_{2} \mathrm{~L}_{2} \mathrm{~L}_{1}$ E. Errors in terms of temperature have been obtained comparing the experimental value with the temperature calculated imposing the experimental pressure of three-phase equilibrium. Errors in terms of pressure have been obtained comparing the experimental value with the pressure calculated imposing the experimental temperature of three-phase equilibrium.

Finally, the last two rows present the comparison along the Critical Curve (CC) of the mixture; errors have been evaluated comparing experimental and calculated values of temperature and pressure at fixed composition of methane. 
Table 6. Quantitative comparison of equilibrium compositions, temperatures and pressures of threephase equilibria, and critical temperatures and pressures for the system $\mathrm{xCH}_{4}+(1-\mathrm{x}) \mathrm{H}_{2} \mathrm{~S}$.

\begin{tabular}{|c|c|c|c|c|c|c|c|c|c|}
\hline \multirow{2}{*}{ Reference } & \multirow{2}{*}{$\mathbf{N}$} & \multirow{2}{*}{$\begin{array}{c}\text { Kind } \\
\text { of data }\end{array}$} & \multirow{2}{*}{$\begin{array}{l}\mathbf{T} \\
\mathbf{K}\end{array}$} & \multirow{2}{*}{$\begin{array}{c}\mathbf{P} \\
\mathbf{M P a}\end{array}$} & \multirow{2}{*}{$x$} & \multirow{2}{*}{$\boldsymbol{y}$} & \multicolumn{3}{|c|}{ PT FLASH } \\
\hline & & & & & & & & $\mathbf{x}$ & $\mathbf{y}$ \\
\hline \multirow{4}{*}{$\begin{array}{l}\text { Reamer et al. } \\
1951^{22}\end{array}$} & \multirow{4}{*}{59} & \multirow{4}{*}{$\begin{array}{l}\mathrm{VL}_{2} \mathrm{E} \\
\mathrm{TPxy}\end{array}$} & \multirow{4}{*}{$277-344$} & \multirow{4}{*}{$1.4-13.4$} & \multirow{4}{*}{$0.0057-0.55$} & \multirow{4}{*}{$0.059-0.73$} & N calc & 57 & 57 \\
\hline & & & & & & & AAD\% & 10.03 & 5.24 \\
\hline & & & & & & & Bias\% & 4.36 & -1.43 \\
\hline & & & & & & & MAD \% & 33.70 & 28.17 \\
\hline \multirow{4}{*}{$\begin{array}{c}\text { Robinson and } \\
\text { Bailey } \\
1957^{23}\end{array}$} & \multirow{4}{*}{3} & \multirow{4}{*}{$\begin{array}{l}\mathrm{VL}_{2} \mathrm{E} \\
\mathrm{TPxy}\end{array}$} & & & & & $\mathbf{N}$ calc & 3 & 3 \\
\hline & & & & & & & AAD\% & 16.48 & 5.38 \\
\hline & & & 310 & $4.1-12.4$ & $0.033-0.20$ & $0.29-0.51$ & Bias\% & 9.83 & -1.93 \\
\hline & & & & & & & MAD \% & 24.41 & 9.69 \\
\hline & & & & & & & $\mathbf{N}$ calc & 51 & 51 \\
\hline Kohn and & & $\mathrm{VL}_{2} \mathrm{E}$ & & & & & AAD \% & 18.31 & 4.29 \\
\hline $\begin{array}{l}\text { Kurata } \\
1958^{25}\end{array}$ & 54 & TPxy & $188-344$ & $1.4-11.0$ & $0.005-0.24$ & $0.10-0.91$ & Bias\% & 13.62 & -2.71 \\
\hline & & & & & & & MAD \% & 87.17 & 31.17 \\
\hline & & & & & & & N calc & 3 & 3 \\
\hline Robinson et al. & 3 & $\mathrm{VL}_{2} \mathrm{E}$ & 277 & $28-110$ & & & AAD\% & 20.56 & 0.31 \\
\hline $1959^{24}$ & 3 & TPxy & 211 & $2.8-11.0$ & $0.023-0.26$ & $0.51-0.72$ & Bias\% & 20.56 & -0.26 \\
\hline & & & & & & & MAD \% & 43.52 & 0.85 \\
\hline & & & & & & & $\mathbf{N}$ calc & 6 & \\
\hline Cheung and & 6 & $\mathrm{~S}_{2} \mathrm{~L}_{1} \mathrm{E}$ & $119-162$ & & $098-099$ & & AAD\% & 1.23 & \\
\hline $1968^{28}$ & 0 & Tx & $119-102$ & & $0.90-0.99$ & & Bias\% & -1.23 & \\
\hline & & & & & & & MAD \% & 2.57 & \\
\hline & & & & & & & $\mathbf{N}$ calc & 42 & 27 \\
\hline Yarim-Agaev & 42 & $\mathrm{VL}_{2} \mathrm{E}$ & (273-273 & $07-118$ & $0001-036$ & م90 0 & AAD\% & 16.34 & 3.53 \\
\hline $\begin{array}{c}\text { et al. } \\
1991^{29}\end{array}$ & 42 & TPxy & $222-213$ & $0.1-11.8$ & $0.001-0.30$ & $0.14-0.90$ & Bias\% & 13.14 & 3.27 \\
\hline & & & & & & & MAD \% & 261.53 & 6.45 \\
\hline & & & & & & & $\mathbf{N}$ calc & 13 & 13 \\
\hline & & $\mathrm{VL}_{2} \mathrm{E}$ & & & & & AAD\% & 4.34 & 0.81 \\
\hline & 14 & TPxy & $186-203$ & $0.5-5.8$ & $0.0091-0.13$ & $0.80-0.98$ & Bias\% & -4.11 & 0.71 \\
\hline Coquelet et al. & & & & & & & MAD \% & 13.17 & 1.77 \\
\hline $2014^{30}$ & & & & & & & $\mathbf{N}$ calc & 11 & 11 \\
\hline & & $\mathrm{L}_{1} \mathrm{~L}_{2} \mathrm{E}$ & & & & & AAD\% & 10.37 & 1.15 \\
\hline & 10 & TPxx & $186-203$ & $0.1-10.8$ & $0.090-0.14$ & $0.85-0.98$ & Bias\% & -10.37 & -0.92 \\
\hline & & & & & & & MAD \% & 16.56 & 5.75 \\
\hline Reference & $\mathbf{N}$ & Kind & $\mathbf{T}$ & $\mathbf{P}$ & & & THRE & -PHAS & EQ. \\
\hline Reterence & $\mathbf{N}$ & of data & $\mathbf{K}$ & MPa & & & & $\mathbf{T}$ & $\mathbf{P}$ \\
\hline & & & & & & & $\mathbf{N}$ calc & 3 & 3 \\
\hline & 3 & $\mathrm{~S}_{\mathrm{J}} \mathrm{VE}^{1}$ & $167-168$ & $205-22$ & & & AAD \% & 0.56 & 3.16 \\
\hline & 3 & $\mathrm{~S}_{2} \mathrm{~L}_{1} \mathrm{VE}$ & $10 /-108$ & $2.05-2.2$ & & & Bias\% & 0.56 & -3.16 \\
\hline & & & & & & & MAD \% & 0.83 & 4.69 \\
\hline & & & & & & & $\mathbf{N}$ calc & 8 & 8 \\
\hline & 8 & $\mathrm{~S}_{\mathrm{J}} \mathrm{VE}^{1}$ & 184-186 & $0.04-201$ & & & AAD\% & 0.93 & $>100$ \\
\hline & & $\mathbf{S}_{2} \mathbf{L}_{2} \mathbf{V E}$ & $184-180$ & $0.04-2.01$ & & & Bias\% & 0.93 & $>100$ \\
\hline Kohn and & & & & & & & MAD \% & 1.46 & $>100$ \\
\hline $\begin{array}{l}\text { Kurata } \\
1958^{25}\end{array}$ & & & & & & & $\mathbf{N}$ calc & 3 & 3 \\
\hline & 3 & $\mathrm{I} \mathrm{VF}^{1}$ & $186-200$ & $36-53$ & & & AAD\% & 0.42 & 1.99 \\
\hline & 3 & $\mathbf{L}_{2} \mathrm{~L}_{1} \mathbf{V E}$ & $180-200$ & $5.0-5.3$ & & & Bias\% & 0.27 & -1.32 \\
\hline & & & & & & & MAD \% & 0.64 & 2.93 \\
\hline & & & & & & & $\mathbf{N}$ calc & 10 & 2 \\
\hline & 10 & $\mathrm{~S}_{\mathrm{J}} \mathrm{J}_{\mathrm{L}} \mathrm{F}^{1}$ & $183-185$ & $603-137$ & & & AAD \% & 0.52 & 28.15 \\
\hline & 10 & $\mathrm{~S}_{2} \mathrm{~L}_{2} \mathrm{~L}_{1} \mathrm{E}$ & $183-185$ & $0.05-15.1$ & & & Bias\% & 0.52 & -28.15 \\
\hline & & & & & & & MAD \% & 0.88 & 46.40 \\
\hline
\end{tabular}




\begin{tabular}{|c|c|c|c|c|c|c|c|c|}
\hline \multirow{2}{*}{ Reference } & \multirow{2}{*}{$\mathbf{N}$} & \multirow{2}{*}{$\begin{array}{c}\text { Kind } \\
\text { of data }\end{array}$} & \multirow{2}{*}{$\begin{array}{l}\text { Tc } \\
\mathbf{K}\end{array}$} & \multirow{2}{*}{$\begin{array}{c}\text { Pc } \\
\text { MPa }\end{array}$} & \multirow{2}{*}{$x$} & \multicolumn{3}{|c|}{ CRITICAL POINTS } \\
\hline & & & & & & & Tc & Pc \\
\hline \multirow{4}{*}{$\begin{array}{c}\text { Reamer et al. } \\
1951^{22}\end{array}$} & \multirow{4}{*}{6} & \multirow{4}{*}{$\begin{array}{l}\text { CC } \\
\text { TPx }\end{array}$} & \multirow{4}{*}{$267-361$} & \multirow{4}{*}{$10.2-13.4$} & \multirow{4}{*}{$0.1-0.6$} & $\mathrm{~N}$ calc & 5 & 5 \\
\hline & & & & & & AAD\% & 1.22 & 1.60 \\
\hline & & & & & & Bias\% & 1.05 & -0.02 \\
\hline & & & & & & MAD \% & 2.00 & 3.09 \\
\hline \multirow{4}{*}{$\begin{array}{c}\text { Kohn and } \\
\text { Kurata } \\
1958^{25}\end{array}$} & \multirow{4}{*}{4} & \multirow{4}{*}{$\begin{array}{l}\text { CC } \\
\text { TPx }\end{array}$} & \multirow{4}{*}{$193-364$} & \multirow{4}{*}{$4.8-12.0$} & \multirow{4}{*}{$0.067-0.97$} & N calc & 4 & 4 \\
\hline & & & & & & AAD\% & 1.89 & 4.58 \\
\hline & & & & & & Bias\% & 1.89 & 1.01 \\
\hline & & & & & & MAD \% & 2.70 & 6.32 \\
\hline
\end{tabular}

${ }^{1}$ Values evaluated from pressure-temperature diagrams prepared from experimental isotherms by cross-plotting at constant percentage of liquid.

According to Table 6, the critical values of Reamer et al. and Kohn and Kurata ${ }^{25}$ are well represented by the model; the maximum MAD considering the two sources of experimental values is about $6 \%$.

The model agrees well also with the values of $\mathrm{S}_{2} \mathrm{~L}_{1} \mathrm{E}$ of Cheung and Zander, ${ }^{28}$ and the $\mathrm{L}_{2} \mathrm{~L}_{1} \mathrm{E}$ values of Coquelet et al. ${ }^{30}$ In this last case, a MAD of about $17 \%$ is found at $186 \mathrm{~K}$ and $3.7 \mathrm{MPa}$ for a composition of methane in the liquid phase lower than 0.1 .

Considering all the $\mathrm{VL}_{2} \mathrm{E}$ experimental values, the methane composition in the vapor phase is represented within an overall AAD of about $5 \%$, the Bias $\%$ is between about $-3 \%$ and $4 \%$, while the highest values of MAD of about $30 \%$ are found with respect to the data of Reamer et al. ${ }^{22}$ and Kohn and Kurata $^{25}$ for two compositions lower than 0.1. Taking into account the deviations in Table 6 related to the composition of the liquid phase mole fraction, it is possible to state that the AAD is always lower than about $21 \%$, and that the MAD is higher than in the vapor phase. Higher percentage deviations are encountered in the liquid phase because of the low $\mathrm{CH}_{4}$ mole fraction. For instance, the MAD of about 34\% (Reamer et al. ${ }^{22}$ ), $87 \%\left(\right.$ Kohn and Kurata $^{25}$ ), and 260\% (Yarim$\operatorname{Agaev}^{29}$ ) are related to experimental liquid compositions of methane of $0.0057,0.0125$, and 0.001 , respectively.

With respect to phase equilibria involving three phases, a good agreement is achieved along the $\mathrm{S}_{2} \mathrm{~L}_{1} \mathrm{VE}$ and $\mathrm{L}_{2} \mathrm{~L}_{1} \mathrm{VE}$ boundaries. The extent to which the pressures of $\mathrm{S}_{2} \mathrm{~L}_{2} \mathrm{~L}_{1} \mathrm{E}$ and $\mathrm{S}_{2} \mathrm{~L}_{2} \mathrm{VE}$ calculated by the SLV EoS deviate from the experimental pressures is a direct consequence of the 
difference between the calculated and the experimental temperature at the quadruple point, as discussed later in this section.

Table 7 presents the quantitative comparison between the SLV EoS and the experimental values (composition of methane, temperature, and pressure) proposed by Kohn and Kurata ${ }^{25}$ concerning the Quadruple Point $\left(\mathrm{S}_{2} \mathrm{~L}_{2} \mathrm{~L}_{1} \mathrm{VE}\right)$ and the Upper Critical EndPoint $\mathrm{L}_{2}\left(\mathrm{~L}_{1}=\mathrm{V}\right)$.

With respect to the QP, the relative percentage errors between calculated and literature values are about $-0.6 \%,-32 \%$, and $2 \%$ for the composition of $\mathrm{CH}_{4}$ in the liquid $\mathrm{L}_{1}$, liquid $\mathrm{L}_{2}$, and vapor phase, respectively; the temperature and pressure of the QP are reproduced by the model within $1 \%$ of deviation. It should be noted that in Ref. 25 the solid phase $\mathrm{S}_{2}$ is treated as pure $\mathrm{H}_{2} \mathrm{~S}$, whereas the calculated mole fraction of methane in the $S_{2}$ phase is 0.046 .

With respect to the $\mathrm{UCEP}_{1}$, the deviations related to the experimental temperature and pressure are about $1.3 \%$ and $2.6 \%$, respectively. For the composition of methane, the errors are $-1.28 \%$ for the $\mathrm{L}_{1}=\mathrm{V}$ phase and $14 \%$ for the $\mathrm{L}_{2}$ phase.

Improved representations could have been obtained using more complex mixing rules involving binary interaction parameters instead of Eqs. 6-8 and/or introducing temperature dependent binary interaction parameters, but authors decided to use a single binary interaction parameter, $k_{i j}$, constant with temperature, to increase the prediction capability of the model. The model is applied in the next section for representing the whole and complex phase diagram of the mixture in a wide range of temperature and pressure even for regions where data are scarce or not at all available. The chosen parameterization of the SLV EoS is then a compromise between the accuracy in representing the existing experimental values and the robustness of the model with respect to extrapolation for predicting the phase diagrams at temperatures and pressures for which experimental values are not available. 
Table 7. Comparison between calculated and the experimental ${ }^{25}$ singular points for the methanehydrogen sulfide system.

\begin{tabular}{|c|c|c|c|c|c|c|}
\hline & $x \mathrm{CH}_{4}$ in $\mathrm{S}_{2}$ & $x \mathrm{CH}_{4}$ in $L_{1}$ & $x \mathrm{CH}_{4}$ in $\mathrm{L}_{2}$ & $x \mathrm{CH}_{4}$ in $\mathrm{V}$ & $T / K$ & $P / M P a$ \\
\hline \multicolumn{7}{|c|}{$\mathrm{QP}\left(\mathrm{S}_{2} \mathrm{~L}_{1} \mathrm{~L}_{2} \mathrm{VE}\right)$} \\
\hline Ref. 25 & 0 & 0.935 & 0.104 & 0.967 & 182.21 & 3.38 \\
\hline SLV EoS & 0.046 & 0.929 & 0.071 & 0.988 & 183.92 & 3.40 \\
\hline err\% & l & -0.64 & -31.73 & 2.17 & 0.94 & 0.59 \\
\hline \multicolumn{7}{|c|}{$\mathrm{UCEP}_{1} \mathrm{~L}_{2}\left(\mathrm{~L}_{1}=\mathrm{V}\right)$} \\
\hline Ref. 25 & l & 0.935 & 0.1 & 0.935 & 199.76 & 5.30 \\
\hline SLV EoS & 1 & 0.923 & 0.114 & 0.923 & 202.25 & 5.44 \\
\hline err\% & / & $-1.28 \%$ & 14.00 & $-1.28 \%$ & 1.25 & 2.64 \\
\hline
\end{tabular}

Figures 3-7 portray some qualitative comparisons between selected experimental values and the model.

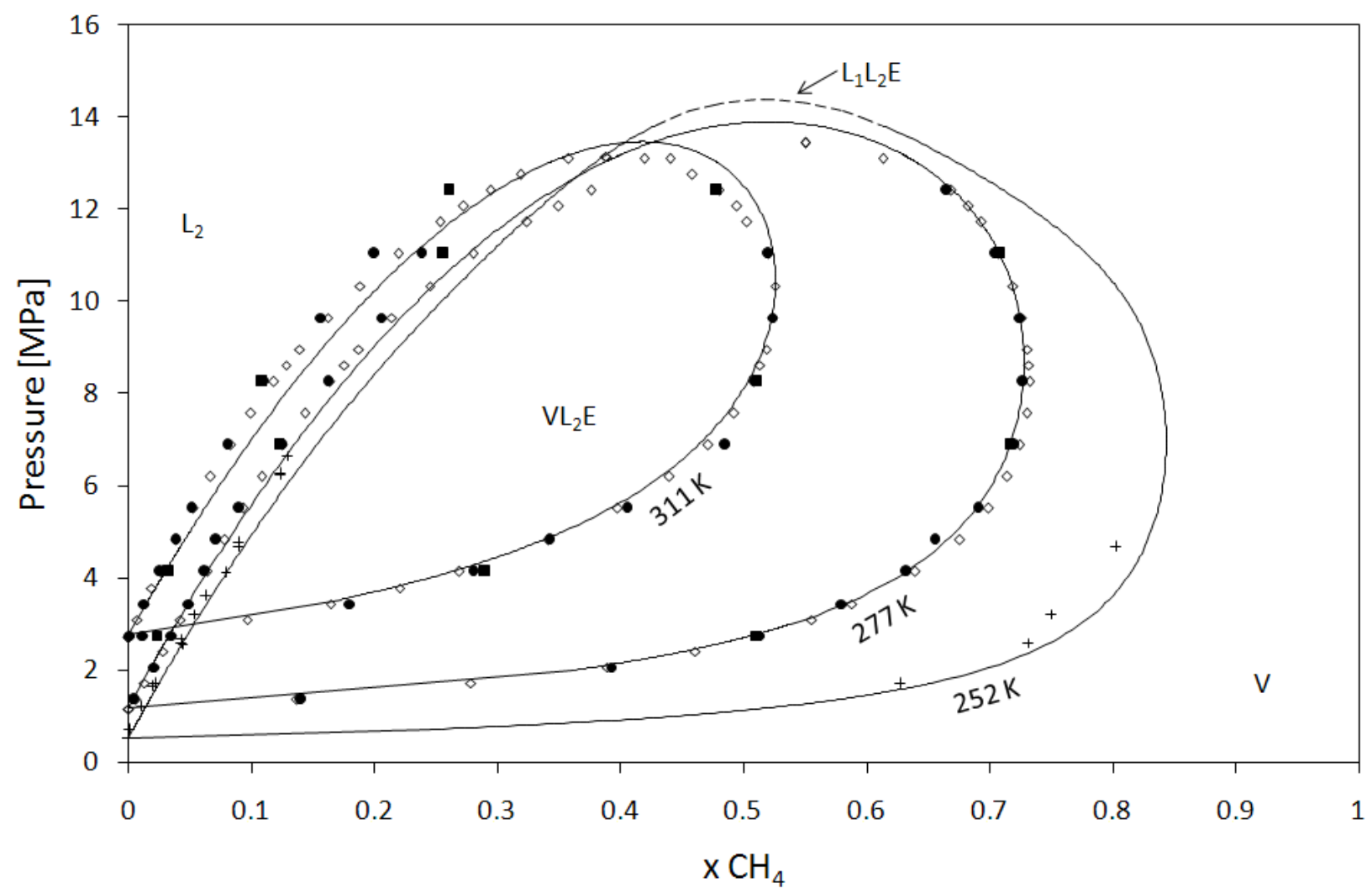

Figure 3. Pressure-composition diagram at $252 \mathrm{~K}, 277 \mathrm{~K}$, and $311 \mathrm{~K}$.

Data: $\diamond:$ Reamer et al. ${ }^{22} ; \bullet:$ Kohn and Kurata ${ }^{25} ; \bullet:$ Robinson et al. ${ }^{24}$, Robinson and Bailey ${ }^{23} ;$ : YarimAgaev $^{29}$. SLV EoS: - : $\mathrm{VL}_{2} \mathrm{E},--: \mathrm{L}_{1} \mathrm{~L}_{2} \mathrm{E}$.

The pressure-composition cross sections in Figure 3 show the agreement of the SLV EoS with $\mathrm{VL}_{2} \mathrm{E}$ data in the range $252-311 \mathrm{~K}$. Data in Figure 3 are rather consistent among them, and the 
model slightly deviates from the experimental composition of methane in the $\mathrm{L}_{2}$ phase when the temperature increases approaching the critical temperature of pure $\mathrm{H}_{2} \mathrm{~S}$.

In Figure 3, the isotherms at $277 \mathrm{~K}$ and $311 \mathrm{~K}$ end at a $\mathrm{V}=\mathrm{L}_{2}$ critical point. To the contrary, at 252 $\mathrm{K}$ the $\mathrm{VL}_{2} \mathrm{E}$ becomes a $\mathrm{L}_{1} \mathrm{~L}_{2} \mathrm{E}$ at about $13.8 \mathrm{MPa}$ and the isotherm ends at a $\mathrm{L}_{1}=\mathrm{L}_{2}$ critical point, thus explaining the odd shape of the isotherm at this temperature with respect to the behaviors at the higher temperatures shown in Figure 3. The dashed line in Figure 3 represents the $\mathrm{L}_{1} \mathrm{~L}_{2} \mathrm{E}$ at $252 \mathrm{~K}$.

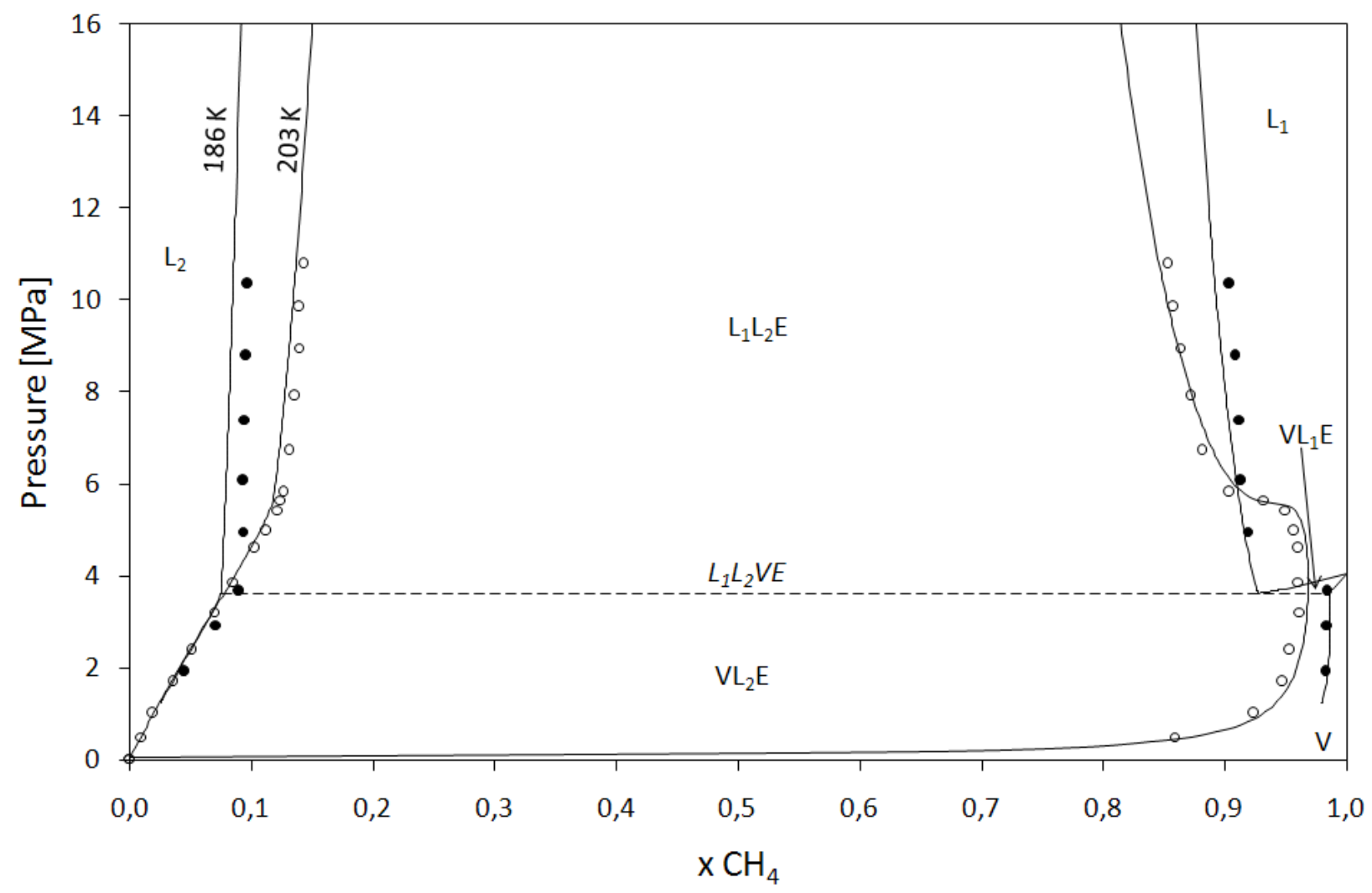

Figure 4. Pressure-composition diagram at $186 \mathrm{~K}$ and $203 \mathrm{~K}$.

SLV EoS: — : VL $\mathrm{V}_{1} \mathrm{E}, \mathrm{VL}_{2} \mathrm{E}$, and $\mathrm{L}_{2} \mathrm{~L}_{1} \mathrm{E} ;--: \mathrm{L}_{2} \mathrm{~L}_{1} \mathrm{VE}$. Data of Coquelet et al. ${ }^{30}: \bullet: 186 \mathrm{~K} ; \circ: 203 \mathrm{~K}$.

Figure 4 presents the qualitative comparison at 186 and $203 \mathrm{~K}$; data are from Coquelet et al. ${ }^{30}$ At $203 \mathrm{~K}$ the system presents immiscibility between two liquid phases $\left(\mathrm{L}_{1}\right.$ and $\left.\mathrm{L}_{2}\right)$, and the one rich in methane $\left(\mathrm{L}_{1}\right)$ becomes a vapor phase in the low pressure region. Being this temperature higher than the calculated temperature of the $\mathrm{UCEP}_{1}(202.25 \mathrm{~K}$ from Table 7$)$, the transition from $\mathrm{L}_{1}$ to the vapor does not involve neither a $\mathrm{VL}_{1} \mathrm{E}$ nor a critical point $\mathrm{L}_{1}=\mathrm{V}$. 
A $\mathrm{VL}_{1} \mathrm{E}$ occurs at any temperature lower than the critical temperature of methane $(190.56 \mathrm{~K})$ and higher than the calculated temperature of the quadruple point $\mathrm{QP}_{1}(183.92 \mathrm{~K}$ from Table 7$)$, as for $186 \mathrm{~K}$ in Figure 4. Furthermore, a $\mathrm{L}_{2} \mathrm{~L}_{1} \mathrm{VE}$ appears because of the immiscibility gap in the liquid phase. The isotherm at $186 \mathrm{~K}$ has not been presented in Figure 4 in the low pressure region seeing that a solid phase and related solid-fluid equilibria are involved there. Nevertheless, next section presents the complete phase equilibrium behavior.

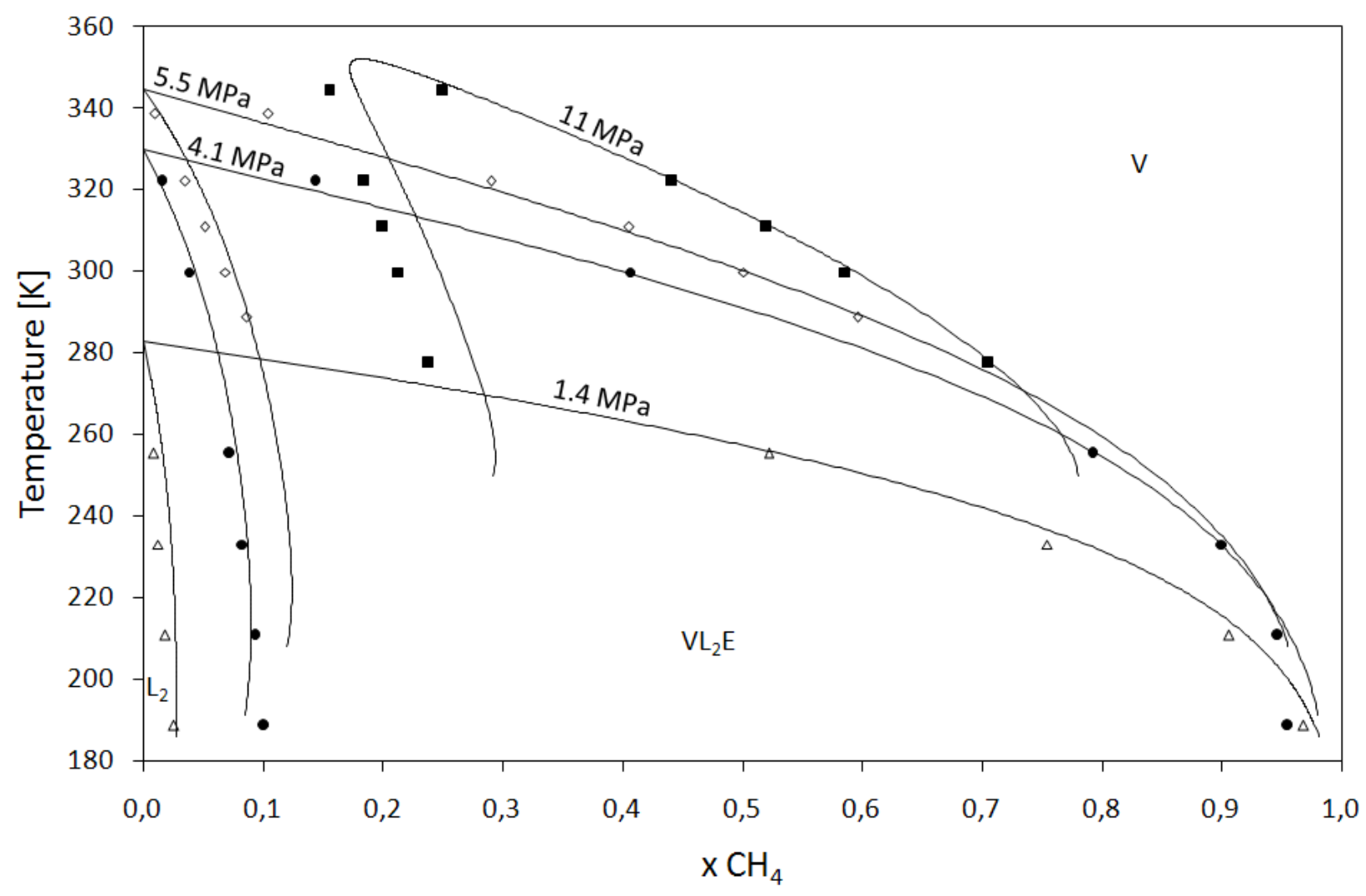

Figure 5. Temperature-composition diagram at 1.4, 4.1, 5.5, and $11 \mathrm{MPa}$.

— : SLV EoS. Data of Kohn and Kurata ${ }^{25}:$ : $11 \mathrm{MPa} ; \diamond: 5.5 \mathrm{MPa} ; \bullet: 4.1 \mathrm{MPa} ; \Delta: 1.4 \mathrm{MPa}$.

The temperature-composition cross sections of Figure 5 show the phase equilibrium behavior of the $\mathrm{CH}_{4}+\mathrm{H}_{2} \mathrm{~S}$ system between $1.4 \mathrm{MPa}$ and $11 \mathrm{MPa}$. Only the $\mathrm{VL}_{2} \mathrm{E}$ has been presented in Figure 5, whereas the low temperature equilibria have been added and discussed in the next section. According to Figure 5, the SLV EoS is in a quite good agreement with data, except for the deviation with respect to the composition of methane in the $\mathrm{L}_{2}$ phase at $11 \mathrm{MPa}$. As a consequence, the 
calculated $\mathrm{L}_{2}=\mathrm{V}$ critical point appears to have a higher methane content than what can be inferred from the experimental values.

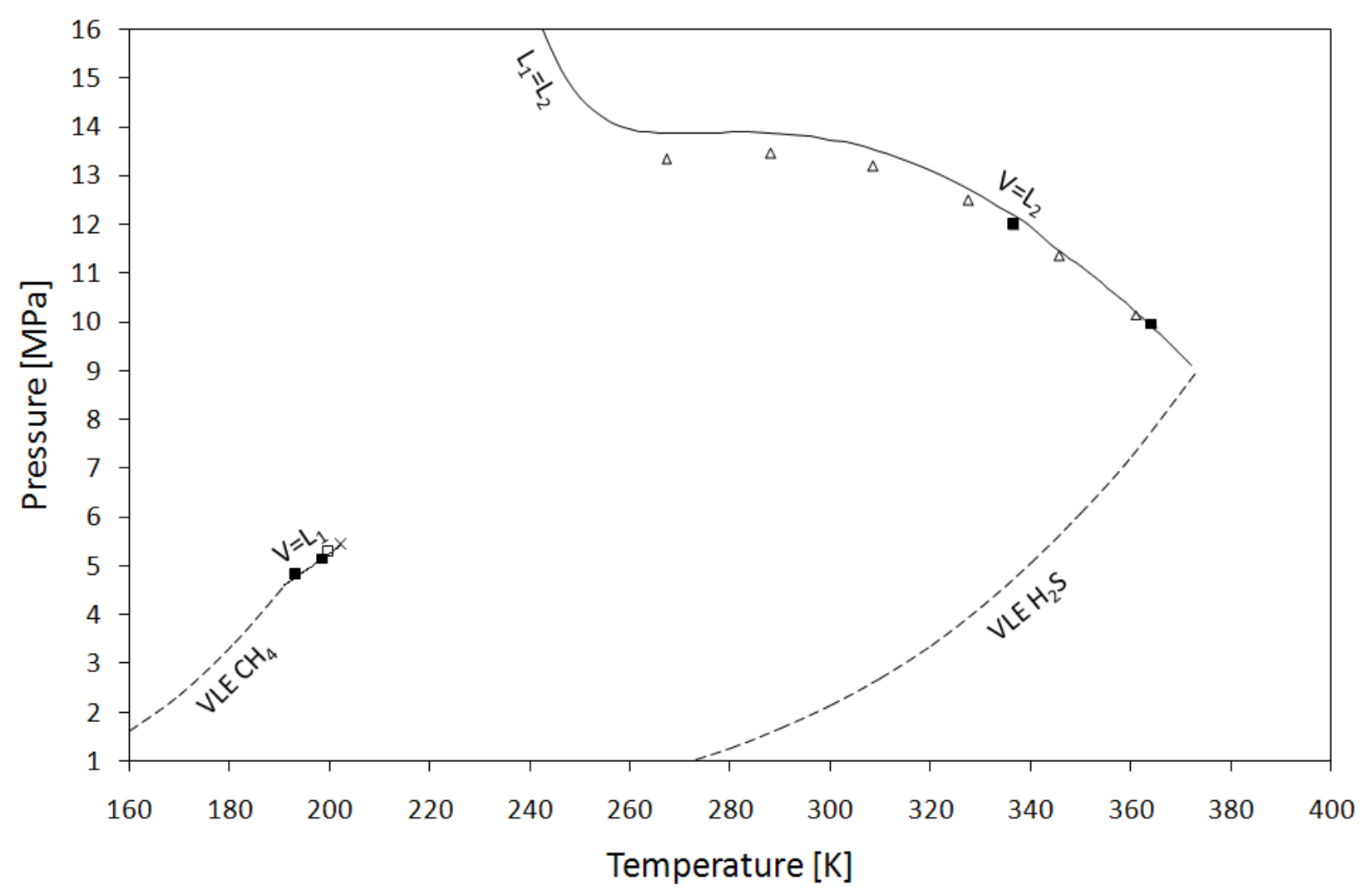

Figure 6. Vapor-liquid and liquid-liquid critical loci for the $\mathrm{CH}_{4}+\mathrm{H}_{2} \mathrm{~S}$ system.

Data: $\mathrm{V}=\mathrm{L}_{1}$ and $\mathrm{V}=\mathrm{L}_{2}: \boldsymbol{\|}:$ Kohn and Kurata ${ }^{25} ; \Delta$ : Reamer et al. ${ }^{22} ; \mathrm{L}_{2}\left(\mathrm{~L}_{1}=\mathrm{V}\right): \square:$ Kohn and Kurata ${ }^{25}$. SLV EoS: - - : VLE of $\mathrm{CH}_{4}$ and $\mathrm{H}_{2} \mathrm{~S} ;-$ : $\mathrm{V}=\mathrm{L}_{1}, \mathrm{~V}=\mathrm{L}_{2}$ and $\mathrm{L}_{1}=\mathrm{L}_{2} ; \times: \mathrm{L}_{2}\left(\mathrm{~L}_{1}=\mathrm{V}\right)$.

Figure 6 illustrates the comparison between calculated and experimental values of the critical points of the mixture. Considering the left-branch of the critical curve (mixtures at higher methane content), deviations concerning the calculated (cross) and experimental (empty square) $\mathrm{UCEP}_{1}$ have been already presented in Table 7 . The calculated $\mathrm{L}_{1}=\mathrm{V}$ critical curve exits the critical point of methane (see Table 2) and rises up to the $\mathrm{UCEP}_{1}$.

The calculated $\mathrm{L}_{2}=\mathrm{V}$ critical curve originates from the critical point of $\mathrm{H}_{2} \mathrm{~S}$ (see Table 2) and reaches firstly a local maximum and then a local minimum in pressure while extending toward the low temperature region. These values (respectively $13.9 \mathrm{MPa}$ and $13.87 \mathrm{MPa}$ ) are located at temperatures higher than about $266 \mathrm{~K}$, temperature where, in the critical curve, the vapor phase 
becomes a liquid phase rich in methane (phase $\mathrm{L}_{1}$ ). As a consequence, the $\mathrm{L}_{2}=\mathrm{L}_{1}$ critical curve replaces the $\mathrm{L}_{2}=\mathrm{V}$ one for temperature lower than $266 \mathrm{~K}$, and it develops in the high pressure region for decreasing temperatures. This $\mathrm{L}_{2}=\mathrm{L}_{1}$ critical curve ends in the singular point $\mathrm{S}_{2}\left(\mathrm{~L}_{2}=\mathrm{L}_{1}\right), \mathrm{UCEP}_{2}$, as discussed in the next section.

With respect to the data of Reamer et al., ${ }^{22}$ the calculated critical curve develops at pressures slightly higher than the experimental values before reaching the inflection point and the $\mathrm{L}_{2}=\mathrm{L}_{1}-$ $\mathrm{L}_{2}=\mathrm{V}$ transition.

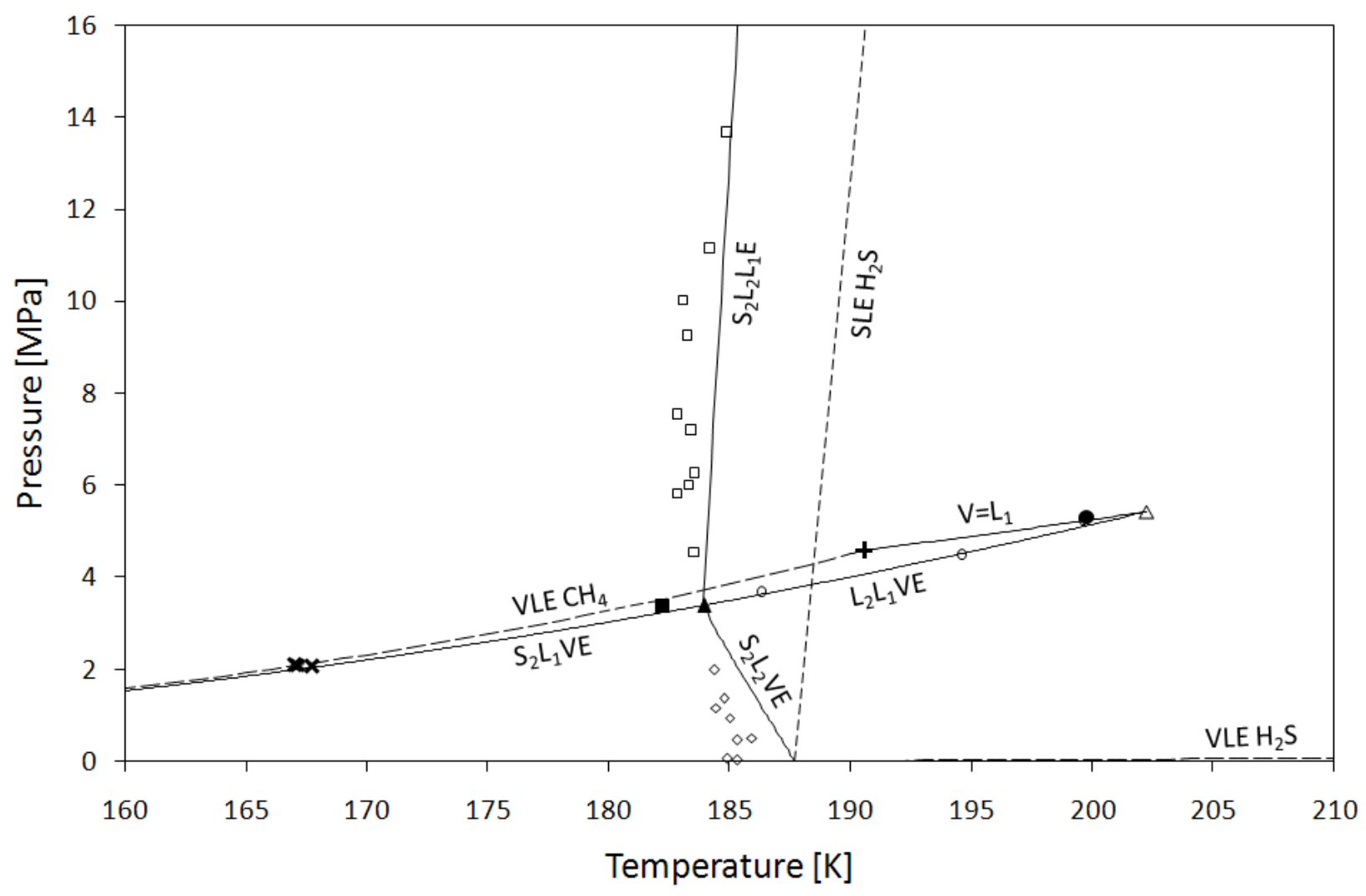

Figure 7. Pressure-temperature phase diagram of the $\mathrm{CH}_{4}+\mathrm{H}_{2} \mathrm{~S}$ system in proximity of the $Q P_{1}$. Data of Kohn and Kurata ${ }^{25}: \diamond: \mathrm{S}_{2} \mathrm{~L}_{2} \mathrm{VE} ; \circ: \mathrm{L}_{2} \mathrm{~L}_{1} \mathrm{VE} ; \square: \mathrm{S}_{2} \mathrm{~L}_{2} \mathrm{~L}_{1} \mathrm{E} ; \times: \mathrm{S}_{2} \mathrm{~L}_{1} \mathrm{VE} ; \boldsymbol{\square}: \mathrm{QP}_{1} ; \bullet: \mathrm{UCEP}_{1}$. SLV EoS : - : three-phase equilibrium and V=L $\mathrm{L}_{1}$ curve; - - : VLE of $\mathrm{CH}_{4}, \mathrm{SLE}$ and VLE of $\mathrm{H}_{2} \mathrm{~S}$; + : critical point of $\mathrm{CH}_{4} ; \boldsymbol{\nabla}$ : triple point of $\mathrm{H}_{2} \mathrm{~S} ; \boldsymbol{\Lambda}: \mathrm{QP}_{1} ; \Delta: \mathrm{UCEP}_{1}$.

Figure 7 groups all the three-phase equilibria of the binary mixture occurring at temperatures higher than $160 \mathrm{~K}$ and pressures up to $16 \mathrm{MPa}$. It should be remarked that being the data in Figure 7 not available numerically, they have been obtained from graphs ${ }^{25}$ by means of a specific software. 
Filled square and circle represent the experimental temperature-pressure couples for the quadruple point and the $\mathrm{UCEP}_{1}$, respectively; correspondent calculated values are the filled triangle and the empty triangle. The dashed curves in Figure 7 are the saturation curves of $\mathrm{CH}_{4}$ and $\mathrm{H}_{2} \mathrm{~S}$, and the melting curve of $\mathrm{H}_{2} \mathrm{~S}$ as calculated by the SLV EoS.

Four three-phase boundaries originate from the calculated QP; the $\mathrm{S}_{2} \mathrm{~L}_{1} \mathrm{VE}$ curve which extends down to $160 \mathrm{~K}$ remaining close to the saturation curve of methane; the $\mathrm{L}_{2} \mathrm{~L}_{1} \mathrm{VE}$ curve ending at the calculated $\mathrm{UCEP}_{1}$; the $\mathrm{S}_{2} \mathrm{~L}_{2} \mathrm{~L}_{1} \mathrm{E}$ curve which rapidly extends in the high pressure region; the $\mathrm{S}_{2} \mathrm{~L}_{2} \mathrm{VE}$ curve which joins the triple point of $\mathrm{H}_{2} \mathrm{~S}(\boldsymbol{\nabla})$. For sake of completeness, the $\mathrm{V}=\mathrm{L}_{1}$ critical curve has been added in Figure 7; it exits the critical point of $\mathrm{CH}_{4}(+)$ and joins the $\mathrm{UCEP}_{1}(\Delta)$.

The deviation between the calculated $\mathrm{S}_{2} \mathrm{~L}_{2} \mathrm{~L}_{1} \mathrm{E}$ and $\mathrm{S}_{2} \mathrm{~L}_{2} \mathrm{VE}$ boundaries and the experimental trends which can be inferred from the correspondent available data (respectively empty squares and diamonds) can be related to the deviation between the calculated and experimental temperature of the QP (see Table 7). Furthermore, the $\mathrm{S}_{2} \mathrm{~L}_{2} \mathrm{VE}$ data ${ }^{25}$ seem not to extend in the low pressure region towards the triple point temperature of pure $\mathrm{H}_{2} \mathrm{~S}(187.7 \mathrm{~K}, 22.3 \mathrm{kPa})$. In fact, the experimental points tend to a temperature of about $185 \mathrm{~K}$ in the zero-pressure limit, temperature that is about 3 degrees lower than the triple point temperature of $\mathrm{H}_{2} \mathrm{~S}$ proposed in Ref. 45. This explains the remarkable deviations for the $\mathrm{S}_{2} \mathrm{~L}_{2} \mathrm{~L}_{1} \mathrm{E}$ and $\mathrm{S}_{2} \mathrm{~L}_{2} V E$ presented in Table 7.

As previously stated, next section aims at presenting an overview of the phase equilibrium behavior of the $\mathrm{CH}_{4}+\mathrm{H}_{2} \mathrm{~S}$ system by means of several isotherms and isobars. With respect to this section, solid phases and correspondent equilibria have been added in cross sections and P-T diagrams in order to present the whole phase equilibrium behavior. 


\section{Description of the Phase Diagram of the Methane-Hydrogen Sulfide System}

This section has the scope of describing the pressure-temperature phase diagram and all the possible types of pressure-composition and temperature-composition phase diagrams that can be encountered in the investigated range of temperature and pressure. This analysis aims to be helpful to the process engineer who needs to understand how the $\mathrm{CH}_{4}+\mathrm{H}_{2} \mathrm{~S}$ system behaves at a certain temperature and pressure.

Figure 8 presents the pressure-temperature phase diagram of the $\mathrm{CH}_{4}+\mathrm{H}_{2} \mathrm{~S}$ mixture for temperatures from $70 \mathrm{~K}$ up to the critical temperature of $\mathrm{H}_{2} \mathrm{~S}$ and pressures up to $250 \mathrm{MPa}$.

According to the available experimental values and the results of the SLV EoS, in these ranges the mixture presents two Quadruple Points and two Upper Critical EndPoints. The QPs are related to the $\mathrm{S}_{2} \mathrm{~S}_{1} \mathrm{~L}_{1} \mathrm{VE}\left(\mathrm{QP}_{2}\right)$ and the $\mathrm{S}_{2} \mathrm{~L}_{2} \mathrm{~L}_{1} \mathrm{VE}\left(\mathrm{QP}_{1}\right)$; the UCEPs are related to the singular points $\mathrm{L}_{2}\left(\mathrm{~L}_{1}=\mathrm{V}\right), \mathrm{UCEP}_{1}$, and the $\mathrm{S}_{2}\left(\mathrm{~L}_{2}=\mathrm{L}_{1}\right), \mathrm{UCEP}_{2}$.

The phase equilibrium behavior involves then 7 three-phase equilibrium boundaries $\left(\mathrm{S}_{2} \mathrm{~S}_{1} \mathrm{VE}\right.$, $\mathrm{S}_{2} \mathrm{~S}_{1} \mathrm{~L}_{1} \mathrm{E}, \mathrm{S}_{1} \mathrm{~L}_{1} \mathrm{VE}, \mathrm{S}_{2} \mathrm{~L}_{1} \mathrm{VE}, \mathrm{S}_{2} \mathrm{~L}_{2} \mathrm{VE}, \mathrm{S}_{2} \mathrm{~L}_{2} \mathrm{~L}_{1} \mathrm{E}$, and $\left.\mathrm{L}_{2} \mathrm{~L}_{1} \mathrm{VE}\right)$ and 5 phases $\left(\mathrm{S}_{2}, \mathrm{~S}_{1}, \mathrm{~L}_{2}, \mathrm{~L}_{1}\right.$, and V).

Taking into account the huge range of pressure considered in this work, the $y$-axis in Figure 8 has been cut twice (at $0.5 \mathrm{MPa}$ and $19 \mathrm{MPa}$ ) for easing the comprehension of the equilibria occurring in proximity of the $\mathrm{QP}_{2}$, of the points $\mathrm{QP}_{1}-\mathrm{UCEP}_{1}$, and the high-pressure equilibria located near the $\mathrm{UCEP}_{2}$. Furthermore, a zoom of Figure 8 has been presented in Figure 9 in order to show the phase equilibrium behavior in the low-pressure region, namely in proximity of the $\mathrm{QP}_{2}$ and the triple point of $\mathrm{CH}_{4}$.

In the low pressure region of Figure $8,0-0.5 \mathrm{MPa}$, the $\mathrm{QP}_{2}$ almost overlaps the triple point of pure methane, than the saturation, melting, and sublimation curves of pure $\mathrm{CH}_{4}$ are not clearly visible being overlapped by the $S_{2} S_{1} V E, S_{2} S_{1} L_{1} E$, and $S_{2} L_{1} V E$ curves. The $S_{2} L_{2} V E$ curve originates at the triple point of $\mathrm{H}_{2} \mathrm{~S}$, and extends at higher pressures with a negative slope.

The more complex part of the phase equilibrium behavior concentrates between $0.5 \mathrm{MPa}$ and 19 MPa. The $S_{2} S_{1} L_{1} E$ remains close to the SLE of $\mathrm{CH}_{4}$, while the $\mathrm{S}_{2} \mathrm{~L}_{1} \mathrm{VE}$ boundary distances itself 
from the saturation curve of $\mathrm{CH}_{4}$ while approaching the filled triangle, which represents the $\mathrm{QP}_{1}$. The $\mathrm{S}_{2} \mathrm{~L}_{2} \mathrm{VE}$, curve originating at the triple point of $\mathrm{H}_{2} \mathrm{~S}$, also ends at the $\mathrm{QP}_{1}$. The other three-phase equilibria joining the $\mathrm{QP}_{1}$ are the $\mathrm{L}_{2} \mathrm{~L}_{1} \mathrm{VE}$ and the $\mathrm{S}_{2} \mathrm{~L}_{2} \mathrm{~L}_{1} \mathrm{E}$. The former reaches the UCEP ${ }_{1}$, namely the empty triangle in Figure 8, the latter extends rapidly at high pressures with a positive slope. In addition to that, two critical boundaries occur: the $\mathrm{V}=\mathrm{L}_{1}$ loci leaving the critical point of $\mathrm{CH}_{4}$ to end in the $\mathrm{UCEP}_{1}$, and the $\mathrm{V}=\mathrm{L}_{2}$ loci originating from the critical point of $\mathrm{H}_{2} \mathrm{~S}$ and becoming the $\mathrm{L}_{2}=\mathrm{L}_{1}$ loci at low temperatures.

In the high pressure region of Figure 8, the $\mathrm{S}_{2} \mathrm{~S}_{1} \mathrm{~L}_{1} \mathrm{E}$ starts to deviate from the SLE of $\mathrm{CH}_{4}$, and the $\mathrm{L}_{2}=\mathrm{L}_{1}$ loci meets the $\mathrm{S}_{2} \mathrm{~L}_{2} \mathrm{~L}_{1} \mathrm{E}$ curve at the empty square, namely the $\mathrm{UCEP}_{2}(208.98 \mathrm{~K}$ and 224.09 $\mathrm{MPa}$ ). As a consequence, the $\mathrm{L}_{2}$ and $\mathrm{L}_{1}$ phases become a unique liquid phase for any pressure higher than the pressure at the $\mathrm{UCEP}_{2}, \mathrm{~S}_{2}\left(\mathrm{~L}_{2}=\mathrm{L}_{1}\right)$. 


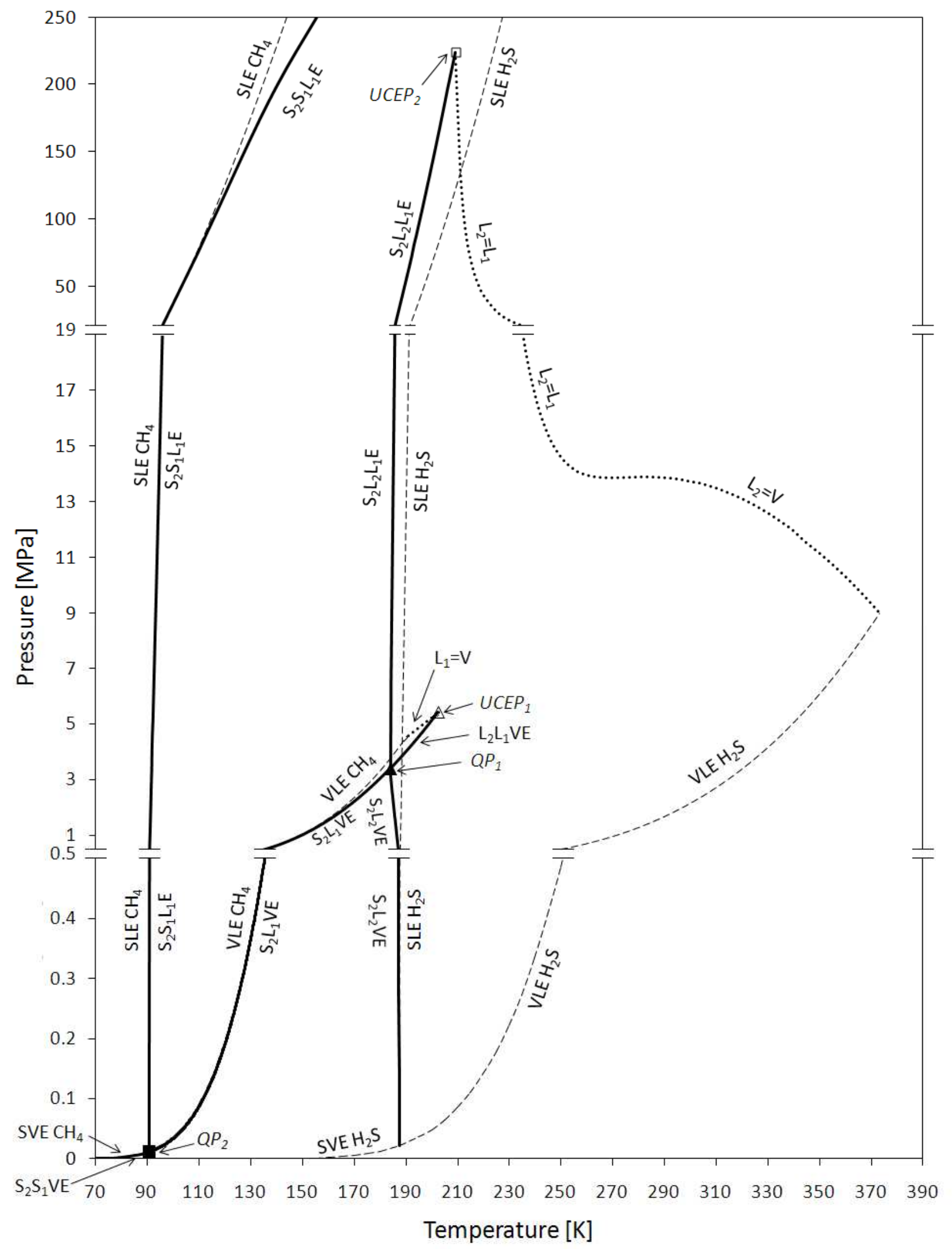

Figure 8. Calculated pressure-temperature phase diagram of the $\mathrm{CH}_{4}+\mathrm{H}_{2} \mathrm{~S}$ system.

- : three-phase equilibrium boundaries; $\cdots$ : critical curves; - - : SVE, VLE and SLE of $\mathrm{CH}_{4}$ and $\mathrm{H}_{2} \mathrm{~S}$; - $: \mathrm{QP}_{2} ; \boldsymbol{\Lambda}: \mathrm{QP}_{1} ; \Delta: \mathrm{UCEP}_{1} ; \square: \mathrm{UCEP}_{2}$. 
The three-phase equilibrium boundaries related to the $\mathrm{QP}_{2}$, calculated at $90.75 \mathrm{~K}$ and $11.77 \mathrm{kPa}$, can be appreciated in Figure 9. From the $\mathrm{QP}_{2}$, the $\mathrm{S}_{2} \mathrm{~S}_{1} \mathrm{VE}$ curve extends in the low temperature region, the $\mathrm{S}_{2} \mathrm{~S}_{1} \mathrm{~L}_{1}$ E extends in the high pressure region, the $\mathrm{S}_{2} \mathrm{~L}_{1} \mathrm{VE}$ curve develops in such a way to end in the $\mathrm{QP}_{1}$, the $\mathrm{S}_{1} \mathrm{~L}_{1} \mathrm{VE}$ joins the triple point of $\mathrm{CH}_{4}$. Dashed curves represent the sublimation, saturation, and melting curves of pure $\mathrm{CH}_{4}$.

It should be stated that any experimental evidence has been provided in the literature concerning the precise position of the $\mathrm{QP}_{2}$, thus the calculated $\mathrm{QP}_{2}$ is a simple result of the SLV EoS with a binary interaction parameter regressed with respect to the available data at high temperatures. The calculated $\mathrm{QP}_{2}$ is at a temperature slightly higher than the triple point temperature of methane, and this feature results in a solid-fluid equilibrium behavior of the peritectic type, as it has been discussed in the following.

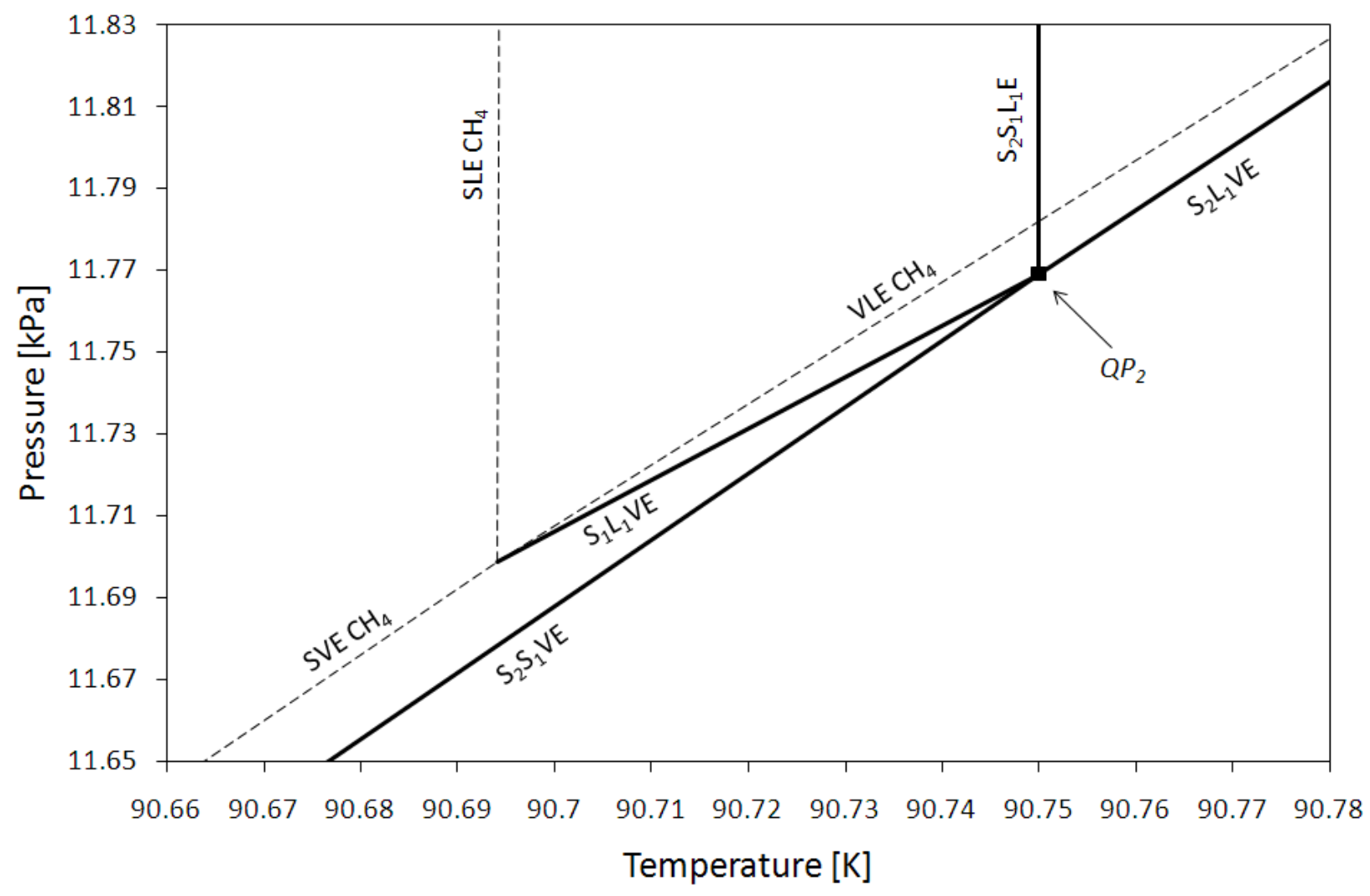

Figure 9. Calculated pressure-temperature phase diagram of the $\mathrm{CH}_{4}+\mathrm{H}_{2} \mathrm{~S}$ system in proximity of the $\mathbf{Q P}_{2}$.

- : $\mathrm{QP}_{2} ;$ - : three-phase equilibrium boundaries; -- : VLE, SVE, and SLE of $\mathrm{CH}_{4}$. 
Figures 10-15 present a series of cross sections at constant temperature and pressure that have been selected in the PT phase diagram (Figure 8) in order to describe all the phase equilibrium behaviors of the mixture in the wide ranges of temperature and pressure considered in this work.

As it has already been stated, the objective is to provide the reader with a mapping of the phase diagram and the possibility of rapidly obtaining an overview of the phase equilibrium behavior according to the system temperature and pressure.

A set of temperature and pressure couples has been selected in order to follow the qualitative changes of the phase behavior, as summarized in Tables 8 and 9.

Table 8 presents all the main regions of temperature (listed from 1T to 13T) where the correspondent pressure-composition cross section does not change from a qualitative point of view. A lower and an upper temperature limit have been fixed for each region of temperature, and a representative temperature (Tref) has been chosen for each interval in order to describe its qualitative phase diagram. The last column of Table 8 indicates the figure presenting the cross section correspondent to the chosen representative temperature. In some cases, either the lower or the upper limit or both temperature limits are represented by the temperature where two phase boundaries meet or cross each other. For instance for the region 4T, the lower limit is the temperature at the quadruple point $\mathrm{QP}_{1}$, whereas the upper is the temperature where the saturation curve of $\mathrm{CH}_{4}\left(\mathrm{VLE} \mathrm{CH}_{4}\right)$ crosses the $\mathrm{S}_{2} \mathrm{~L}_{2} \mathrm{~L}_{1} \mathrm{E}$ curve. 
Table 8. Temperature ranges presenting different qualitative pressure-composition phase equilibrium behaviors for the methane-hydrogen sulfide system, and the selected representative temperature (Tref).

\begin{tabular}{|c|c|c|c|c|}
\hline Region & Lower limit $(T / K)$ & Upper limit $(T / K)$ & Tref / K & Figure \\
\hline $1 \mathrm{~T}$ & Low-temperature limit (70) & $\mathrm{T}_{\mathrm{t}} \mathrm{CH}_{4}(90.694)$ & 85 & $10 \mathrm{~A}$ \\
\hline $2 \mathrm{~T}$ & $\mathrm{~T}_{\mathrm{t}} \mathrm{CH}_{4}(90.694)$ & $\mathrm{T} \mathrm{QP}_{2}(90.75)$ & 90.7 & 10B \\
\hline $3 \mathrm{~T}$ & $\mathrm{~T} \mathrm{QP}_{2}(90.75)$ & $\mathrm{T} \mathrm{QP}_{1}(183.92)$ & 140 & $10 \mathrm{C}$ \\
\hline $4 \mathrm{~T}$ & $\mathrm{~T} \mathrm{QP}_{1}(183.92)$ & $\mathrm{T}$ cross VLE $\mathrm{CH}_{4} / \mathrm{S}_{2} \mathrm{~L}_{2} \mathrm{~L}_{1} \mathrm{E}(184.13)$ & 183.94 & 10D \\
\hline $5 \mathrm{~T}$ & $\mathrm{~T}$ cross VLE $\mathrm{CH}_{4} / \mathrm{S}_{2} \mathrm{~L}_{2} \mathrm{~L}_{1} \mathrm{E}(184.13)$ & $\mathrm{T}_{\mathrm{t}} \mathrm{H}_{2} \mathrm{~S}(187.7)$ & 186.25 & $10 \mathrm{E}$ \\
\hline $6 \mathrm{~T}$ & $\mathrm{~T}_{\mathrm{t}} \mathrm{H}_{2} \mathrm{~S}(187.7)$ & $\mathrm{T}$ cross $\mathrm{SLE} \mathrm{H}_{2} \mathrm{~S} / \mathrm{L}_{2} \mathrm{~L}_{1} \mathrm{VE}(188.47)$ & 188 & $10 \mathrm{~F}$ \\
\hline $7 \mathrm{~T}$ & $\mathrm{~T}$ cross SLE $\mathrm{H}_{2} \mathrm{~S} / \mathrm{L}_{2} \mathrm{~L}_{1} \mathrm{VE}(188.47)$ & $\mathrm{T}$ cross $\mathrm{VLE} \mathrm{CH}_{4} / \mathrm{SLE} \mathrm{H}_{2} \mathrm{~S}(188.56)$ & 188.48 & $11 \mathrm{~A}$ \\
\hline $8 \mathrm{~T}$ & $\mathrm{~T}$ cross VLE $\mathrm{CH}_{4} / \mathrm{SLE} \mathrm{H}_{2} \mathrm{~S}(188.56)$ & $\mathrm{T}_{\mathrm{c}} \mathrm{CH}_{4}(190.56)$ & 189.5 & $11 \mathrm{~B}$ \\
\hline $9 \mathrm{~T}$ & $\mathrm{~T}_{\mathrm{c}} \mathrm{CH}_{4}(190.56)$ & T UCEP $_{1}(202.25)$ & 195 & $11 \mathrm{C}$ \\
\hline $10 \mathrm{~T}$ & $\mathrm{~T} \mathrm{UCEP}_{1}(202.25)$ & $\mathrm{T} \mathrm{UCEP}_{2}(208.98)$ & 203.4 & $11 \mathrm{D}$ \\
\hline $11 \mathrm{~T}$ & $\mathrm{~T} \mathrm{UCEP}_{2}(208.98)$ & $\mathrm{T}$ cross SLE $\mathrm{H}_{2} \mathrm{~S} / \mathrm{L}_{2}=\mathrm{L}_{1}(210.71)$ & 210 & $11 \mathrm{E}$ \\
\hline $12 \mathrm{~T}$ & \multirow{2}{*}{$\mathrm{T}$ cross SLE $\mathrm{H}_{2} \mathrm{~S} / \mathrm{L}_{2}=\mathrm{L}_{1}(210.71)$} & \multirow{2}{*}{$\mathrm{T}_{\mathrm{c}} \mathrm{H}_{2} \mathrm{~S}(373.1)$} & 230 & $11 \mathrm{~F}$ \\
\hline $13 \mathrm{~T}$ & & & 300 & 12 \\
\hline
\end{tabular}

A $S_{2} V E$, a $S_{1} V E$, and a $S_{2} S_{1} E$ occur at any temperature higher than $70 \mathrm{~K}$ and lower than the triple point temperature of methane, as shown in the Pressure-composition (Px) cross section at $85 \mathrm{~K}$, Figure 10A. At this temperature, the binary mixture presents a region of $\mathrm{S}_{2} \mathrm{VE}$ for all pressures lower than $4.911 \mathrm{kPa}$ down to the sublimation pressure of pure $\mathrm{H}_{2} \mathrm{~S}$. An equilibrium between the phases $S_{2}, S_{1}$, and $V$ occurs at $4.911 \mathrm{kPa}$. Then, the $\mathrm{S}_{2} \mathrm{~S}_{1} \mathrm{E}$ extends up to $250 \mathrm{MPa}$, while the $\mathrm{S}_{1} \mathrm{VE}$ ends at the sublimation pressure of pure $\mathrm{CH}_{4}(4.913 \mathrm{kPa})$.

With respect to the range $1 \mathrm{~T}$, any Px cross section in the range $2 \mathrm{~T}$ presents one additional pressure of three-phase equilibrium. This is related to the $S_{1} L_{1} V E$.

Figure $10 \mathrm{~B}$ shows the phase equilibrium behavior at $90.7 \mathrm{~K}$ : the $\mathrm{S}_{2} \mathrm{~S}_{1} \mathrm{~V}_{1} \mathrm{E}$ and $\mathrm{S}_{1} \mathrm{~L}_{1} \mathrm{VE}$ are at 11.694 $\mathrm{kPa}$ and $11.705 \mathrm{kPa}$, respectively. The $\mathrm{S}_{2} \mathrm{VE}$ extends again from the sublimation pressure of $\mathrm{H}_{2} \mathrm{~S}$ $\left(1.3 \times 10^{-6} \mathrm{kPa}\right)$ up to the pressure of $\mathrm{S}_{2} \mathrm{~S}_{1} \mathrm{VE}$, and the $\mathrm{S}_{2} \mathrm{~S}_{1} \mathrm{E}$ extends up to $250 \mathrm{MPa}$ and beyond. In this case, the $S_{1} V E$ ends at the $S_{1} L_{1} V E$ rather than at the sublimation of $\mathrm{CH}_{4}$; the $\mathrm{VL}_{1} \mathrm{E}$ and the $\mathrm{S}_{1} \mathrm{~L}_{1} \mathrm{E}$ end respectively at the saturation $(11.708 \mathrm{kPa})$ and melting $(40.13 \mathrm{kPa})$ pressures of pure $\mathrm{CH}_{4}$.

Any Px cross section in the range $3 \mathrm{~T}$ is qualitatively represented in Figure 10C, which has been calculated at $140 \mathrm{~K}$. The $\mathrm{S}_{2} \mathrm{VE}$ originating at the sublimation pressure of $\mathrm{H}_{2} \mathrm{~S}$ ends now at the pressure of $\mathrm{S}_{2} \mathrm{~L}_{1} \mathrm{VE}(0.635 \mathrm{MPa})$ : from this pressure, the $\mathrm{VL}_{1} \mathrm{E}$ joins the saturation pressure of $\mathrm{CH}_{4}$ 
$(0.647 \mathrm{MPa})$, while the $\mathrm{S}_{2} \mathrm{~L}_{1} \mathrm{E}$ extends in the high pressure region up to the $\mathrm{S}_{2} \mathrm{~S}_{1} \mathrm{~L}_{1} \mathrm{E}$ (198 MPa). From this three-phase equilibrium, the $\mathrm{S}_{1} \mathrm{~L}_{1} \mathrm{E}$ ends at the melting pressure of $\mathrm{CH}_{4}(230 \mathrm{MPa})$, the $\mathrm{S}_{2} \mathrm{~S}_{1} \mathrm{E}$ extends in the high pressure region.

When the system temperature exceeds $183.92 \mathrm{~K}$, namely the temperature of $\mathrm{QP}_{1}$, a liquid phase $\mathrm{L}_{2}$ appears in order to provide the $\mathrm{S}_{2} \mathrm{~L}_{2} \mathrm{VE}$, the $\mathrm{L}_{2} \mathrm{~L}_{1} \mathrm{VE}$, the $\mathrm{S}_{2} \mathrm{~L}_{2} \mathrm{~L}_{1} \mathrm{E}$, and the related two-phase equilibria. The Px cross section at $183.94 \mathrm{~K}$ in Figure 10D presents a $\mathrm{S}_{2} \mathrm{VE}$ ending at the pressure of $\mathrm{S}_{2} \mathrm{~L}_{2} \mathrm{VE}$ (3.374 MPa). The system is at $\mathrm{S}_{2} \mathrm{~L}_{2} \mathrm{E}$ between this pressure and the pressure of $\mathrm{S}_{2} \mathrm{~L}_{2} \mathrm{~L}_{1} \mathrm{E}$ (3.645 MPa) only for compositions of $\mathrm{CH}_{4}$ between about 0.04 and 0.07 . To the contrary, the $\mathrm{VL}_{2} \mathrm{E}$ and $\mathrm{L}_{2} \mathrm{~L}_{1} \mathrm{E}$ occur for higher contents of $\mathrm{CH}_{4}$, and the transition between these equilibria involves the $\mathrm{L}_{2} \mathrm{~L}_{1} \mathrm{VE}$ (3.402 MPa). The $\mathrm{S}_{2} \mathrm{~L}_{1} \mathrm{E}$ originates from the $\mathrm{S}_{2} \mathrm{~L}_{2} \mathrm{~L}_{1} \mathrm{E}$ and extends up to $250 \mathrm{MPa}$ and beyond, while a $\mathrm{VL}_{1} \mathrm{E}$ runs from the pressure of $\mathrm{L}_{2} \mathrm{~L}_{1} \mathrm{VE}$ and the saturation pressure of $\mathrm{CH}_{4}(3.768$ $\mathrm{MPa})$.

In the region $4 \mathrm{~T}$ the saturation pressure of $\mathrm{CH}_{4}$ is higher than the pressure of $\mathrm{S}_{2} \mathrm{~L}_{2} \mathrm{~L}_{1} \mathrm{E}$, while the contrary occurs in the region $5 \mathrm{~T}$, where the phase $\mathrm{L}_{2}$ develops and reaches higher pressures thus making the $\mathrm{S}_{2} \mathrm{~L}_{2} \mathrm{~L}_{1} \mathrm{E}$ occurring at higher pressures. For instance at $186.25 \mathrm{~K}$ (Figure 10E), the pressure of $\mathrm{S}_{2} \mathrm{~L}_{2} \mathrm{~L}_{1} \mathrm{E}$ is $23.449 \mathrm{MPa}$, higher than the saturation pressure of $\mathrm{CH}_{4}(4.045 \mathrm{MPa})$.

In general, all the solid-liquid-vapor equilibria occur once the temperature is higher than the triple point temperature of $\mathrm{CH}_{4}$; the $\mathrm{S}_{2} \mathrm{~L}_{2} \mathrm{E}$ develops between the pressures of $\mathrm{S}_{2} \mathrm{~L}_{2} \mathrm{VE}$ and $\mathrm{S}_{2} \mathrm{~L}_{2} \mathrm{~L}_{1} \mathrm{E}$ in regions $4 \mathrm{~T}$ and $5 \mathrm{~T}$, whereas it starts at the melting pressure of $\mathrm{H}_{2} \mathrm{~S}$ in all the PT cross sections from the region $6 \mathrm{~T}$ to higher temperatures. For instance at $188 \mathrm{~K}$, Figure $10 \mathrm{~F}$, the $\mathrm{S}_{2} \mathrm{~L}_{2} \mathrm{E}$ exits the melting pressure of $\mathrm{H}_{2} \mathrm{~S}(1.632 \mathrm{MPa})$ and ends at the $\mathrm{S}_{2} \mathrm{~L}_{2} \mathrm{~L}_{1} \mathrm{E}$ (37.439 MPa); furthermore, the $\mathrm{VL}_{2} \mathrm{E}$ extends from the $\mathrm{L}_{2} \mathrm{~L}_{1} \mathrm{VE}(3.808 \mathrm{MPa})$ down to the saturation pressure of $\mathrm{H}_{2} \mathrm{~S}(0.0228 \mathrm{MPa})$.

The underlying difference between the phase equilibrium behaviors in the regions $6 \mathrm{~T}-8 \mathrm{~T}$ is the reciprocal positions of the melting pressure of $\mathrm{H}_{2} \mathrm{~S}$, the pressures of $\mathrm{L}_{2} \mathrm{~L}_{1} \mathrm{VE}$, and the saturation pressure of $\mathrm{CH}_{4}$. 
In the region $6 \mathrm{~T}$, the melting pressure of $\mathrm{H}_{2} \mathrm{~S}$ is lower than the pressure of $\mathrm{L}_{2} \mathrm{~L}_{1} \mathrm{VE}$ and the saturation pressure of $\mathrm{CH}_{4}$. In the region $7 \mathrm{~T}$, the melting pressure of $\mathrm{H}_{2} \mathrm{~S}$ exceeds the pressure of $\mathrm{L}_{2} \mathrm{~L}_{1} \mathrm{VE}$ remaining lower than the saturation pressure of $\mathrm{CH}_{4}$. For instance, in the Px cross section at 188.48 K, Figure 11A, these values are 4.222 MPa, 3.859 MPa, and 4.326 MPa, respectively. 

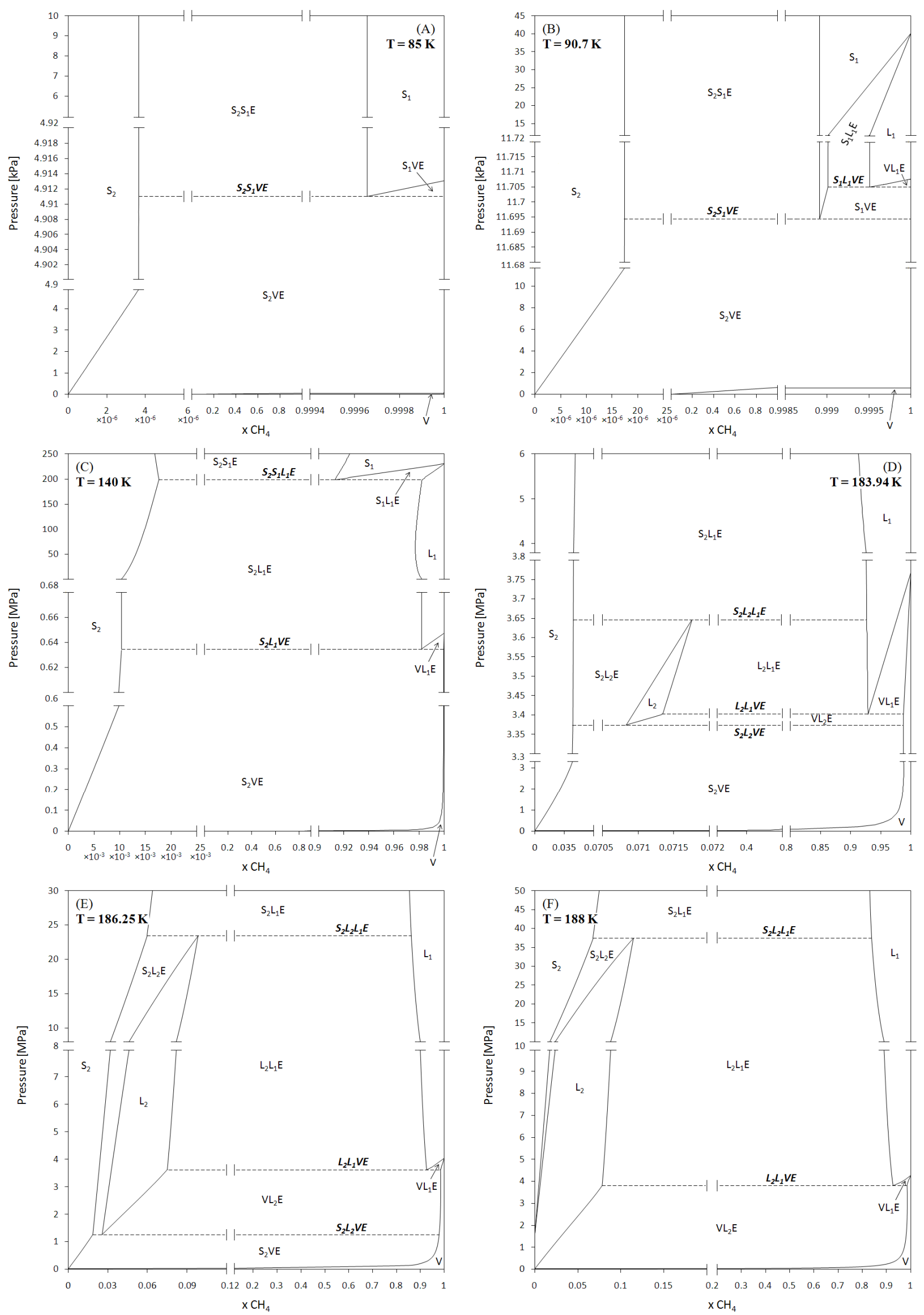

Figure 10. Calculated pressure-composition (Px) cross sections for the regions 1T-6T. 
The melting pressure of $\mathrm{H}_{2} \mathrm{~S}$ exceeds also the saturation pressure of pure $\mathrm{CH}_{4}$ in the region $8 \mathrm{~T}$; for instance, in the Px cross section at $189.5 \mathrm{~K}$ (Figure $11 \mathrm{~B})$ these values are 9.786 $\mathrm{MPa}\left(\mathrm{SLE} \mathrm{H}_{2} \mathrm{~S}\right)$, 4.458 $\mathrm{MPa}\left(\mathrm{VLE} \mathrm{CH} \mathrm{CH}_{4}\right)$, and 4.326 $\mathrm{MPa}\left(\mathrm{L}_{2} \mathrm{~L}_{1} \mathrm{VE}\right)$, respectively.

The upper temperature related to the region $8 \mathrm{~T}$ is the critical temperature of $\mathrm{CH}_{4}$. As a consequence, the $\mathrm{VL}_{1} \mathrm{E}$ ends at the saturation pressure of pure $\mathrm{CH}_{4}$ in all the Px cross sections in the range of temperatures corresponding to the regions from $2 \mathrm{~T}$ to $8 \mathrm{~T}$. The $\mathrm{VL}_{1} \mathrm{E}$ ends instead at a critical point $\mathrm{L}_{1}=\mathrm{V}$ in region 9T, as it can be appreciated in Figure 11C which shows the Px cross section at 195 K. At this temperature, the calculated $\mathrm{L}_{2} \mathrm{~L}_{1} \mathrm{VE}$ and the $\mathrm{S}_{2} \mathrm{~L}_{2} \mathrm{~L}_{1} \mathrm{E}$ are at $4.57 \mathrm{MPa}$ and $94.718 \mathrm{MPa}$, respectively.

According to the PT diagram of Figure 9, the $\mathrm{L}_{2} \mathrm{~L}_{1}$ VE boundary ends at the singular point UCEP 1 . Consequently, the transition between the $\mathrm{V}$ and $\mathrm{L}_{1}$ phases becomes continuous for temperatures higher than 202.25 K. For instance, the Px cross section at $203.4 \mathrm{~K}$ portrayed in Figure 11D illustrates the absence of the $\mathrm{VL}_{1} \mathrm{E}$ and of the critical point $\mathrm{L}_{1}=\mathrm{V}$. The difference between the $\mathrm{VL}_{2} \mathrm{E}$ and the $\mathrm{L}_{2} \mathrm{~L}_{1} \mathrm{E}$ is the consequence of a change in density of the phase at equilibrium with the phase $\mathrm{L}_{2}$. Furthermore, the $\mathrm{S}_{2} \mathrm{~L}_{2} \mathrm{~L}_{1} \mathrm{E}$ occurs at $169.717 \mathrm{MPa}$.

No critical point exists for the mixture in the region $10 \mathrm{~T}$; to the contrary, the $\mathrm{L}_{2}=\mathrm{L}_{1} / \mathrm{V}=\mathrm{L}_{2}$ critical curve is crossed at each temperature higher than the temperature at the $\mathrm{UCEP}_{2}(208.98 \mathrm{~K})$.

At $210 \mathrm{~K}$, Figure $11 \mathrm{E}$, the $\mathrm{VL}_{2} \mathrm{E}$ originates at the saturation pressure of $\mathrm{H}_{2} \mathrm{~S}$, and the $\mathrm{L}_{2} \mathrm{~L}_{1} \mathrm{E}$ ends at a critical point $\mathrm{L}_{2}=\mathrm{L}_{1}(176.4 \mathrm{MPa})$. The $\mathrm{S}_{2} \mathrm{~L}_{2} \mathrm{E}$ exits the melting pressure of $\mathrm{H}_{2} \mathrm{~S}(139.74 \mathrm{MPa})$ and extends in the high pressure region. It should be noted that the melting pressure of $\mathrm{H}_{2} \mathrm{~S}$ is lower than the pressure of the critical point $\mathrm{L}_{2}=\mathrm{L}_{1}$ at $210 \mathrm{~K}$, and so for all the temperatures in the region $11 \mathrm{~T}$. In the region $12 \mathrm{~T}$ the critical point of the system is placed at a pressure lower than the melting pressure of pure $\mathrm{H}_{2} \mathrm{~S}$; for instance at $230 \mathrm{~K}$, Figure $11 \mathrm{~F}$, the $\mathrm{L}_{2} \mathrm{~L}_{1} \mathrm{E}$ ends at about $23 \mathrm{MPa}$, which represents a critical point $\mathrm{L}_{2}=\mathrm{L}_{1}$; the solid-liquid equilibria are located at pressures higher $250 \mathrm{MPa}$. 
Finally, the extent of the $\mathrm{L}_{2} \mathrm{~L}_{1} \mathrm{E}$ reduces for temperatures approaching the critical temperature of $\mathrm{H}_{2} \mathrm{~S}$, and the critical point $\mathrm{L}_{2}=\mathrm{L}_{1}$ becomes a critical point $\mathrm{L}_{2}=\mathrm{V}$, as shown in Figure 12 by the Px cross section at $300 \mathrm{~K}$. 

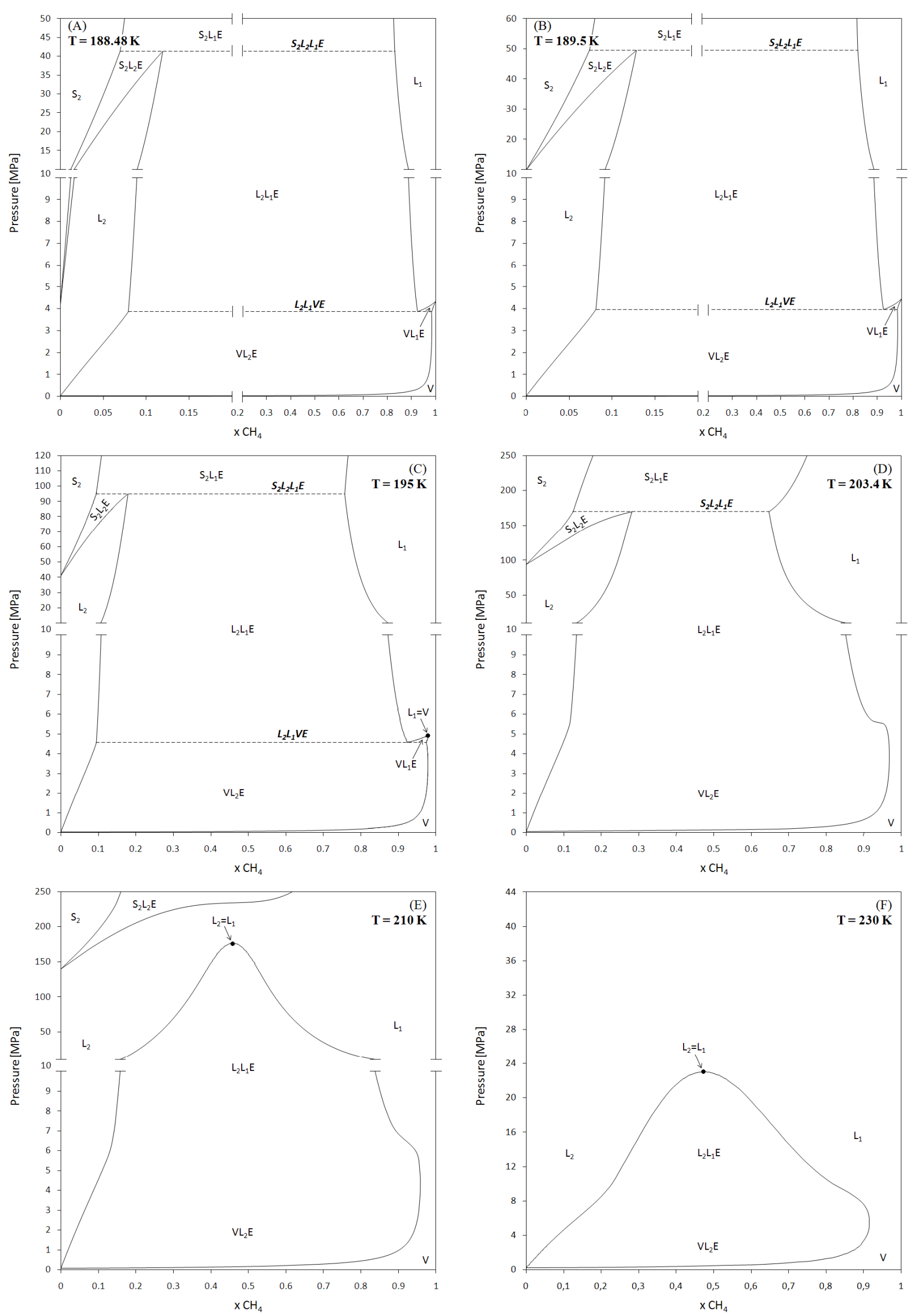

Figure 11. Calculated pressure-composition (Px) cross sections for the regions 7T-12T. 


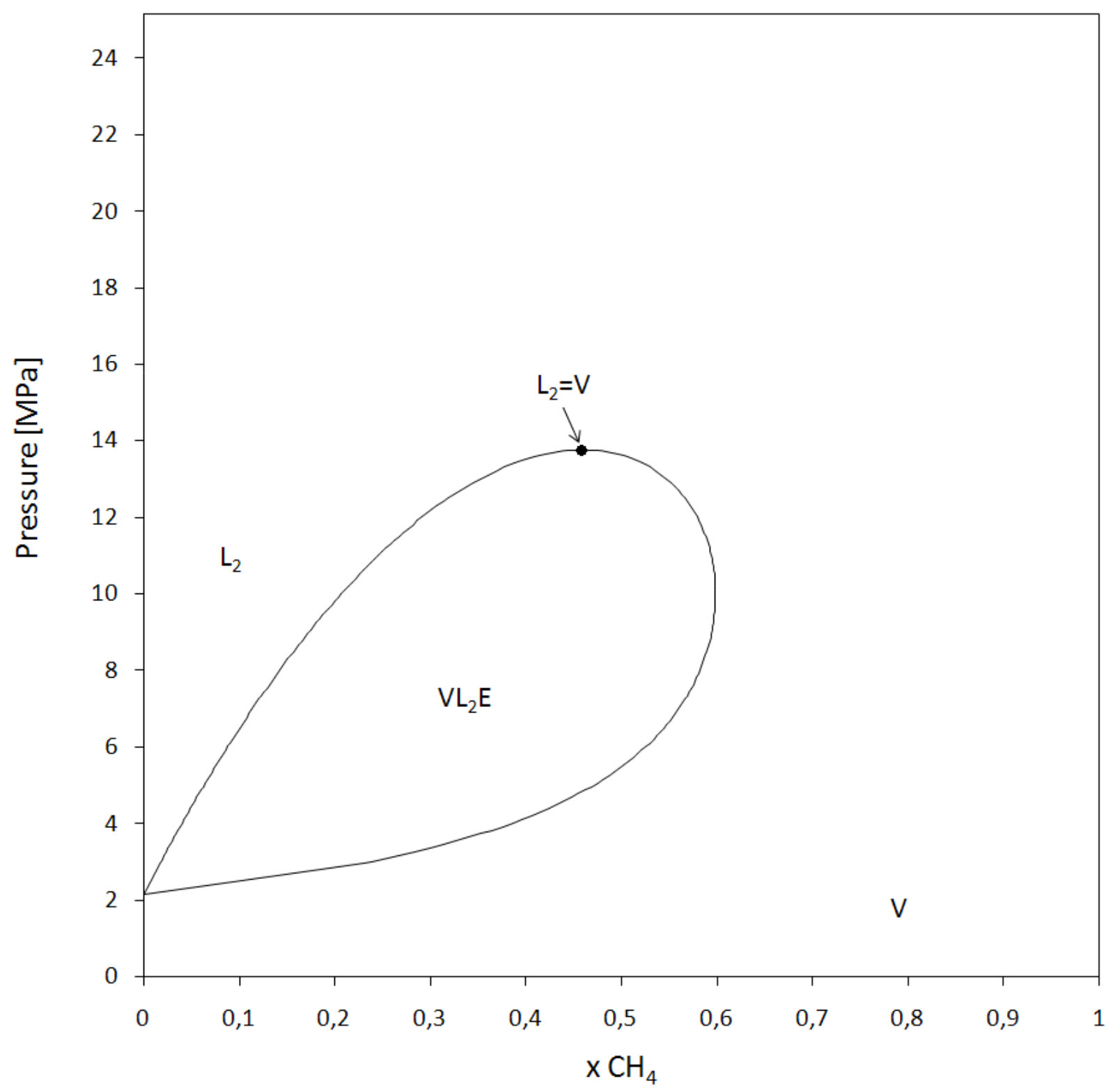

Figure 12. Calculated pressure-composition (Px) cross section at $300 \mathrm{~K}$, i.e. the reference temperature for the region 13T. 
A similar study has been carried out with respect to the qualitative changes of the temperaturecomposition cross sections with pressure. Table 9 summarizes the main pressure regions listed from 1P to 13P. Lower and upper pressure limits and a reference pressure have been fixed for each region of pressure, whereas the last column of Table 9 indicates the number of the figure presenting the correspondent cross section.

In some case, either the lower or the upper limit or both pressure limits are represented by the pressure where two phase boundaries cut cross each other. For instance, the lower limit for the region $5 \mathrm{P}$ is the pressure at the quadruple point $\mathrm{QP}_{1}$, whereas its upper limit is the pressure where the melting curve of $\mathrm{H}_{2} \mathrm{~S}\left(\mathrm{SLE} \mathrm{H}_{2} \mathrm{~S}\right)$ crosses the $\mathrm{L}_{2} \mathrm{~L}_{1} \mathrm{VE}$ curve.

Table 9. Pressure ranges presenting different qualitative temperature-composition phase equilibrium behaviors for the methane-hydrogen sulfide system, and the selected representative pressure (Pref).

\begin{tabular}{|c|c|c|c|c|}
\hline Region & Lower limit $(\mathrm{P} / \mathrm{MPa})$ & Upper limit $(\mathrm{P} / \mathrm{MPa})$ & Pref/MPa & Figure \\
\hline $1 \mathrm{P}$ & Low-pressure limit (0) & $\mathrm{P}_{\mathrm{t}} \mathrm{CH}_{4}(0.011697)$ & 0.009 & $13 \mathrm{~A}$ \\
\hline $2 \mathrm{P}$ & $\mathrm{P}_{\mathrm{t}} \mathrm{CH}_{4}(0.011697)$ & $\mathrm{P} \mathrm{QP}_{2}(0.01177)$ & 0.0117335 & 13B \\
\hline $3 \mathrm{P}$ & $\mathrm{P} \mathrm{QP}_{2}(0.01177)$ & $\mathrm{P}_{\mathrm{t}} \mathrm{H}_{2} \mathrm{~S}(0.0223)$ & 0.02 & $13 \mathrm{C}$ \\
\hline $4 \mathrm{P}$ & $\mathrm{P}_{\mathrm{t}} \mathrm{H}_{2} \mathrm{~S}(0.0223)$ & $\mathrm{P} \mathrm{QP}_{1}(3.4)$ & 1.37 & $13 \mathrm{D}$ \\
\hline $5 \mathrm{P}$ & $\mathrm{P} \mathrm{QP}_{1}(3.4)$ & $\mathrm{P}$ cross $\mathrm{SLE} \mathrm{H}_{2} \mathrm{~S} / \mathrm{L}_{2} \mathrm{~L}_{1} \mathrm{VE}(3.8)$ & 3.75 & $13 \mathrm{E}$ \\
\hline $6 \mathrm{P}$ & $\mathrm{P}$ cross $\mathrm{SLE} \mathrm{H}_{2} \mathrm{~S} / \mathrm{L}_{2} \mathrm{~L}_{1} \mathrm{VE}(3.8)$ & $\mathrm{P}$ cross $\mathrm{VLE} \mathrm{CH}_{4} / \mathrm{S}_{2} \mathrm{~L}_{2} \mathrm{~L}_{1} \mathrm{E}(3.85)$ & 3.825 & $13 \mathrm{~F}$ \\
\hline $7 \mathrm{P}$ & $\mathrm{P}$ cross $\mathrm{VLE} \mathrm{CH}_{4} / \mathrm{S}_{2} \mathrm{~L}_{2} \mathrm{~L}_{1} \mathrm{E}(3.85)$ & $\mathrm{P}$ cross $\mathrm{VLE} \mathrm{CH}_{4} / \mathrm{SLE}_{2} \mathrm{~S}$ (4.34) & 4.14 & $14 \mathrm{~A}$ \\
\hline $8 \mathrm{P}$ & $\mathrm{P}$ cross $\mathrm{VLE} \mathrm{CH}_{4} / \mathrm{SLE}_{2} \mathrm{~S}$ (4.34) & $\mathrm{P}_{\mathrm{c}} \mathrm{CH}_{4}(4.5992)$ & 4.5 & 14B \\
\hline $9 \mathrm{P}$ & $\mathrm{P}_{\mathrm{c}} \mathrm{CH}_{4}(4.5992)$ & $\mathrm{P} \mathrm{UCEP}_{1}(5.44)$ & 5 & $14 \mathrm{C}$ \\
\hline $10 \mathrm{P}$ & $\mathrm{P} \mathrm{UCEP}_{1}(5.44)$ & $\mathrm{P}_{\mathrm{c}} \mathrm{H}_{2} \mathrm{~S}(9)$ & 7.5 & 14D \\
\hline $11 \mathrm{P}$ & $\mathrm{P}_{\mathrm{c}} \mathrm{H}_{2} \mathrm{~S}(9)$ & $\mathrm{P}$ cross SLE $\mathrm{H}_{2} \mathrm{~S} / \mathrm{L}_{2}=\mathrm{L}_{1}(144.46)$ & 15 & $14 \mathrm{E}$ \\
\hline $12 \mathrm{P}$ & $\mathrm{P}$ cross $\mathrm{SLE} \mathrm{H}_{2} \mathrm{~S} / \mathrm{L}_{2}=\mathrm{L}_{1}(144.46)$ & $\mathrm{P} \mathrm{UCEP}_{2}(224.09)$ & 200 & $14 \mathrm{~F}$ \\
\hline $13 \mathrm{P}$ & $\mathrm{P} \mathrm{UCEP}_{2}(224.09)$ & High-pressure limit (250) & 235 & 15 \\
\hline
\end{tabular}

At $9 \mathrm{kPa}$ (Figure 13A) the system $\mathrm{CH}_{4}+\mathrm{H}_{2} \mathrm{~S}$ presents a $\mathrm{S}_{2} \mathrm{~S}_{1} \mathrm{VE}$ at $88.906 \mathrm{~K}$; a $\mathrm{S}_{2} \mathrm{~S}_{1} \mathrm{E}$ extends down to $70 \mathrm{~K}$, whereas the $\mathrm{S}_{2} \mathrm{VE}$ and the $\mathrm{S}_{1} \mathrm{VE}$ ends at the sublimation temperature of pure $\mathrm{H}_{2} \mathrm{~S}(175.957$ $\mathrm{K})$ and $\mathrm{CH}_{4}(88.902 \mathrm{~K})$, respectively. The Temperature-composition (Tx) cross section of Figure $13 \mathrm{~A}$ is representative of the region $1 \mathrm{P}$, whose upper pressure limit is the triple point of $\mathrm{CH}_{4}$.

At any pressure in the region $2 \mathrm{P}$, namely between the triple point pressure of $\mathrm{CH}_{4}(11.697 \mathrm{kPa}) \mathrm{up}$ to the pressure of the $\mathrm{QP}_{2}(11.77 \mathrm{kPa})$, the $\mathrm{S}_{1} \mathrm{VE}$ exists between a $\mathrm{S}_{1} \mathrm{~L}_{1} \mathrm{VE}$ and a $\mathrm{S}_{2} \mathrm{~S}_{1} \mathrm{VE}$. For instance at $11.7335 \mathrm{kPa}$, Figure $13 \mathrm{~B}$, the $\mathrm{S}_{1} \mathrm{VE}$ is confined in the high-methane content region 
between $90.72 \mathrm{~K}$ (temperature of $\mathrm{S}_{1} \mathrm{~L}_{1} \mathrm{VE}$ ) and $90.722 \mathrm{~K}$ (temperature of $\mathrm{S}_{2} \mathrm{~S}_{1} \mathrm{VE}$ ). From the $\mathrm{S}_{1} \mathrm{~L}_{1} \mathrm{VE}$, a $\mathrm{S}_{1} \mathrm{~L}_{1} \mathrm{E}$ and a $\mathrm{VL}_{1} \mathrm{E}$ originate and join the melting temperature $(90.695 \mathrm{~K})$ and the saturation temperature $\left(90.718 \mathrm{~K}\right.$ ) of pure $\mathrm{CH}_{4}$, respectively. The $\mathrm{S}_{2} \mathrm{VE}$ originating at the $\mathrm{S}_{2} \mathrm{~S}_{1} \mathrm{VE}$ always ends at the sublimation temperature of $\mathrm{H}_{2} \mathrm{~S}(179.22 \mathrm{~K}$ in the case of Figure 13B).

A $S_{2} S_{1} L_{1} E$ and a $S_{2} L_{1} V E$ appear when the system pressure exceeds the pressure at $\mathrm{QP}_{2}$ remaining lower than the triple point pressure of $\mathrm{H}_{2} \mathrm{~S}$, as shown in the Tx cross section at $0.02 \mathrm{MPa}$ portrayed in Figure 13C. Figure $13 \mathrm{C}$ is representative of the phase equilibrium behavior in the region 3P, and the temperatures of $\mathrm{S}_{2} \mathrm{~S}_{1} \mathrm{~L}_{1} \mathrm{E}$ and a $\mathrm{S}_{2} \mathrm{~L}_{1} \mathrm{VE}$ at $0.02 \mathrm{MPa}$ are $90.748 \mathrm{~K}$ and $95.14 \mathrm{~K}$, respectively.

The $\mathrm{S}_{1} \mathrm{VE}$ does not exist for pressures higher than the pressure of the $\mathrm{QP}_{2}$, and for increasing pressures the $S_{2} S_{1} L_{1} E$ remains located almost at the same temperature while the $S_{2} L_{1} V E$ moves to higher values. Furthermore, a $\mathrm{S}_{2} \mathrm{~L}_{1} \mathrm{E}$ appears for the first time in the region $3 \mathrm{P}$ and it will never disappear in the Tx cross sections at higher pressures. With respect to the behavior in the region $2 \mathrm{P}$ (Figure 13B) where the $\mathrm{S}_{1} \mathrm{~L}_{1} \mathrm{E}$ and a $\mathrm{VL}_{1} \mathrm{E}$ both join the temperature of $\mathrm{S}_{1} \mathrm{~L}_{1} \mathrm{VE}$, in the region 3P the $\mathrm{S}_{1} \mathrm{~L}_{1} \mathrm{E}$ and a $\mathrm{VL}_{1} \mathrm{E}$ reach two different three-phase equilibria. According to Figure $13 \mathrm{C}$, the $\mathrm{S}_{1} \mathrm{~L}_{1} \mathrm{E}$ ranges from the melting temperature of $\mathrm{CH}_{4}(90.694 \mathrm{~K})$ and the temperature of $\mathrm{S}_{2} \mathrm{~S}_{1} \mathrm{~L}_{1} \mathrm{E}$, while the $\mathrm{VL}_{1} \mathrm{E}$ extends from the saturation temperature of $\mathrm{CH}_{4}(95.136 \mathrm{~K})$ and the temperature of $\mathrm{S}_{2} \mathrm{~L}_{1} \mathrm{VE}$. A third three-phase equilibrium, the $\mathrm{S}_{2} \mathrm{~L}_{2} \mathrm{VE}$, is encountered for pressures in the region $4 \mathrm{P}$, namely from the triple point pressure of $\mathrm{H}_{2} \mathrm{~S}(22.3 \mathrm{kPa})$ up to the pressure of $\mathrm{QP}_{1}$ (3.4 MPa). This additional equilibrium and its related two-phase equilibria $\left(\mathrm{S}_{2} \mathrm{~L}_{2} \mathrm{E}\right.$ and $\left.\mathrm{VL}_{2} \mathrm{E}\right)$ are the consequence of the appearance of the liquid phase $\mathrm{L}_{2}$ in the Tx cross section, as shown at 1.37 MPa in Figure 13D. Thus, in the region $4 \mathrm{P}$, the phase equilibrium behavior changes qualitatively in the high temperature region. With respect to Figure 13C, in Figure 13D the $\mathrm{S}_{2} \mathrm{VE}$ reaches the $\mathrm{S}_{2} \mathrm{~L}_{2} \mathrm{VE}(157.132 \mathrm{~K})$, from which the $\mathrm{S}_{2} \mathrm{~L}_{2} \mathrm{E}$ and $\mathrm{VL}_{2} \mathrm{E}$ continue up to the melting temperature $(186.112 \mathrm{~K}$ ) and saturation temperature (282.753 K) of $\mathrm{H}_{2} \mathrm{~S}$, respectively. 
The $\mathrm{S}_{2} \mathrm{~L}_{1} \mathrm{VE}$ and $\mathrm{S}_{2} \mathrm{~L}_{2} \mathrm{VE}$ cease to occur when the system pressure becomes higher than the pressure of $\mathrm{QP}_{1}$, while the $\mathrm{S}_{2} \mathrm{~S}_{1} \mathrm{~L}_{1} \mathrm{E}$ persists at low temperatures. To the contrary, two different three-phase equilibria turn out, at least for pressures lower than the pressure of $\mathrm{UCEP}_{1}(5.44 \mathrm{MPa})$.

For instance at 3.75 $\mathrm{MPa}$, whose Tx cross section is presented in Figure 13E, the system is characterized by a $\mathrm{S}_{2} \mathrm{~S}_{1} \mathrm{~L}_{1} \mathrm{E}(91.778 \mathrm{~K})$, a $\mathrm{S}_{2} \mathrm{~L}_{2} \mathrm{~L}_{1} \mathrm{E}(183.95 \mathrm{~K})$, and a $\mathrm{L}_{2} \mathrm{~L}_{1} \mathrm{VE}(187.428 \mathrm{~K})$, and related two-phase equilibria. Consequently, it can be stated that the immiscibility between the $\mathrm{L}_{1}$ and $\mathrm{L}_{2}$ phases occurs only for pressures higher than the pressure of $\mathrm{QP}_{1}$, according obviously to the value of the system temperature. The Tx cross sections in Figures 13F, 14A, and 14B are qualitatively of the same kind of Figure 13E. The difference among the correspondent phase equilibrium behaviors (respectively at $3.75 \mathrm{MPa}, 3.825 \mathrm{MPa}, 4.14 \mathrm{MPa}$, and 4.5 $\mathrm{MPa}$ ) is the position of the saturation and/or melting temperatures of the pure components.

At $3.75 \mathrm{MPa}$, Figure 13E, the melting temperature of $\mathrm{H}_{2} \mathrm{~S}(188.393 \mathrm{~K})$ is higher than the temperature of $\mathrm{L}_{2} \mathrm{~L}_{1} \mathrm{VE}(187.428 \mathrm{~K})$, which in turns is higher than the temperatures of $\mathrm{S}_{2} \mathrm{~L}_{2} \mathrm{~L}_{1} \mathrm{E}$ $(183.95 \mathrm{~K})$ and saturation of $\mathrm{CH}_{4}(183.787 \mathrm{~K})$. 

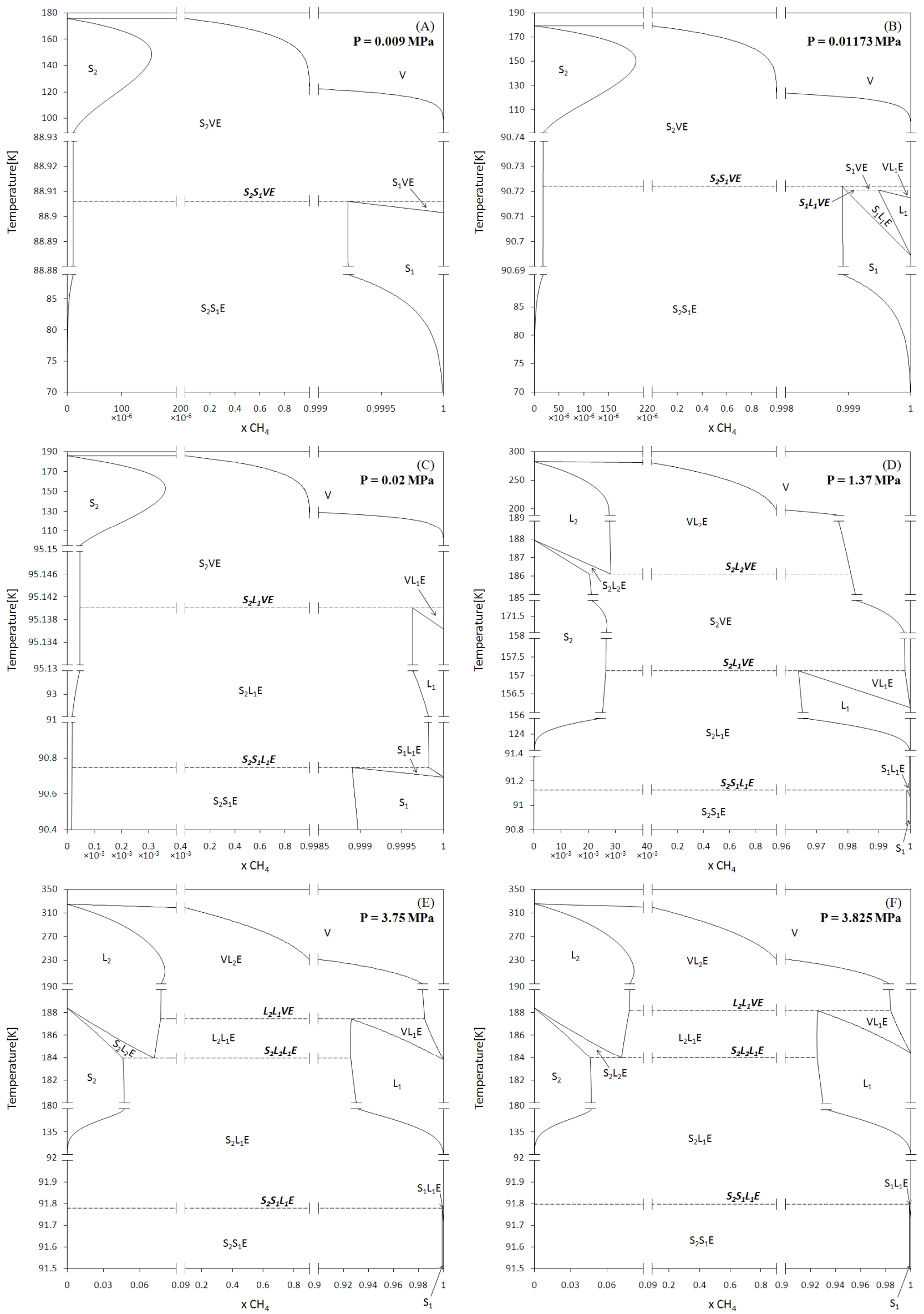

Figure 13. Calculated temperature-composition ( $\mathrm{Tx}$ ) cross sections for the regions 1P-6P. 
At $3.825 \mathrm{MPa}$, Figure $13 \mathrm{~F}$, the melting temperature of $\mathrm{H}_{2} \mathrm{~S}(188.407 \mathrm{~K})$ is still higher than the temperature of $\mathrm{L}_{2} \mathrm{~L}_{1} \mathrm{VE}(188.156 \mathrm{~K})$, and the saturation temperature of $\mathrm{CH}_{4}(184.425 \mathrm{~K})$ is in this case lower than the temperature of $\mathrm{L}_{2} \mathrm{~L}_{1} \mathrm{VE}$ but higher than the temperature of $\mathrm{S}_{2} \mathrm{~L}_{2} \mathrm{~L}_{1} \mathrm{E}(183.958$ $\mathrm{K})$.

At $4.14 \mathrm{MPa}$, Figure $14 \mathrm{~A}$, the temperature of $\mathrm{L}_{2} \mathrm{~L}_{1} \mathrm{VE}(191.09 \mathrm{~K})$ exceeds the melting temperature of $\mathrm{H}_{2} \mathrm{~S}(188.464 \mathrm{~K})$; the saturation temperature of $\mathrm{CH}_{4}(186.99 \mathrm{~K})$ and the temperature of $\mathrm{S}_{2} \mathrm{~L}_{2} \mathrm{~L}_{1} \mathrm{E}$ $(183.98 \mathrm{~K})$ are again lower than the melting temperature of $\mathrm{H}_{2} \mathrm{~S}$.

At 4.5 MPa, Figure 14B, the temperatures of $\mathrm{L}_{2} \mathrm{~L}_{1} \mathrm{VE}(194.379 \mathrm{~K})$ and saturation of $\mathrm{CH}_{4}(189.815$ $\mathrm{K})$ are both higher than the temperatures of melting of $\mathrm{H}_{2} \mathrm{~S}(188.531 \mathrm{~K})$ and of $\mathrm{S}_{2} \mathrm{~L}_{2} \mathrm{~L}_{1} \mathrm{E}(184.022$ $\mathrm{K})$.

The region 9P involves the appearance of the critical point $\mathrm{L}_{1}=\mathrm{V}$. The Tx cross section at $5 \mathrm{MPa}$ in Figure $14 \mathrm{C}$ is representative of the phase equilibrium behavior in this region of pressure. In this case, the $\mathrm{VL}_{1} \mathrm{E}$ joining the $\mathrm{L}_{2} \mathrm{~L}_{1} \mathrm{VE}$ at $198.672 \mathrm{~K}$ does not end at the saturation temperature of $\mathrm{CH}_{4}$ seeing that the system pressure is now higher than the critical point pressure of same component (4.5992 MPa). Therefore the $\mathrm{VL}_{1} \mathrm{E}$ ends at a critical point $\mathrm{L}_{1}=\mathrm{V}$ at about $197.093 \mathrm{~K}$.

It should be noted that in Figures $13 \mathrm{D}-13 \mathrm{~F}$ and $14 \mathrm{~A}-14 \mathrm{C}$ the $\mathrm{S}_{1} \mathrm{~L}_{1} \mathrm{E}$ is confined in the region of high-methane content, and that the temperature of $\mathrm{S}_{2} \mathrm{~L}_{2} \mathrm{~L}_{1} \mathrm{E}$ changes from $91.125 \mathrm{~K}$ at $1.37 \mathrm{MPa}$ (Figure 13D) to $92.12 \mathrm{~K}$ at $5 \mathrm{MPa}$ (Figure 14C).

In the $\mathrm{Tx}$ cross section, a $\mathrm{L}_{1}=\mathrm{V}$ critical point occurs at each pressure between the critical point pressure of $\mathrm{CH}_{4}$ and the pressure of $\mathrm{UCEP}_{1}(5.44 \mathrm{MPa})$. It means that for higher pressures, as in the region 10P represented by the diagram at $7.5 \mathrm{MPa}$ in Figure $14 \mathrm{D}$, the transition between the $\mathrm{L}_{1}$ and the vapor is continuous, thus the $\mathrm{L}_{2} \mathrm{~L}_{1} \mathrm{VE}$ ceases to exist.

Nevertheless, a critical point exists when the pressure is higher than the critical pressure of $\mathrm{H}_{2} \mathrm{~S}$ (9 $\mathrm{MPa})$ and lower than the pressure of $\mathrm{UCEP}_{2}(224.09 \mathrm{MPa})$. This critical point represents either a $\mathrm{L}_{2}=\mathrm{V}$ or a $\mathrm{L}_{2}=\mathrm{L}_{1}$ equality according to pressure. For instance, at $15 \mathrm{MPa}$, Figure $14 \mathrm{E}$, the $\mathrm{VL}_{2} \mathrm{E}$ 
ends at a critical point $\mathrm{L}_{2}=\mathrm{V}(363.3 \mathrm{~K})$, while at $200 \mathrm{MPa}$, Figure $14 \mathrm{~F}$, the $\mathrm{VL}_{2} \mathrm{E}$ has disappeared and the $\mathrm{L}_{2} \mathrm{~L}_{1} \mathrm{E}$ ends directly at a critical point $\mathrm{L}_{2}=\mathrm{L}_{1}(209.53 \mathrm{~K})$.

In Figures $14 \mathrm{C}-14 \mathrm{~F}$, the solid-liquid equilibria $S_{2} L_{2} E$ and $S_{1} L_{1} E$ join the $S_{2} L_{2} L_{1} E$ and the $S_{2} S_{1} L_{1} E$, respectively. The $S_{2} L_{2} E$ ends at the melting temperature of $H_{2} S$, the $S_{1} L_{1} E$ ends at the melting temperature of $\mathrm{CH}_{4}$.

Because the immiscibility in the liquid phase ceases at pressures higher than the pressure of $\mathrm{UCEP}_{2}$ (224.09 MPa), it follows that the $\mathrm{S}_{2} \mathrm{~L}_{2} \mathrm{~L}_{1} \mathrm{E}$ does not persist in the region 13P, as it happens at 235 MPa, Figure 15. This feature leads to have a homogeneous liquid phase and a $S_{2} L E$ extending in the low temperature region down to the $\mathrm{S}_{2} \mathrm{~S}_{1} \mathrm{~L}_{1} \mathrm{E}$. 

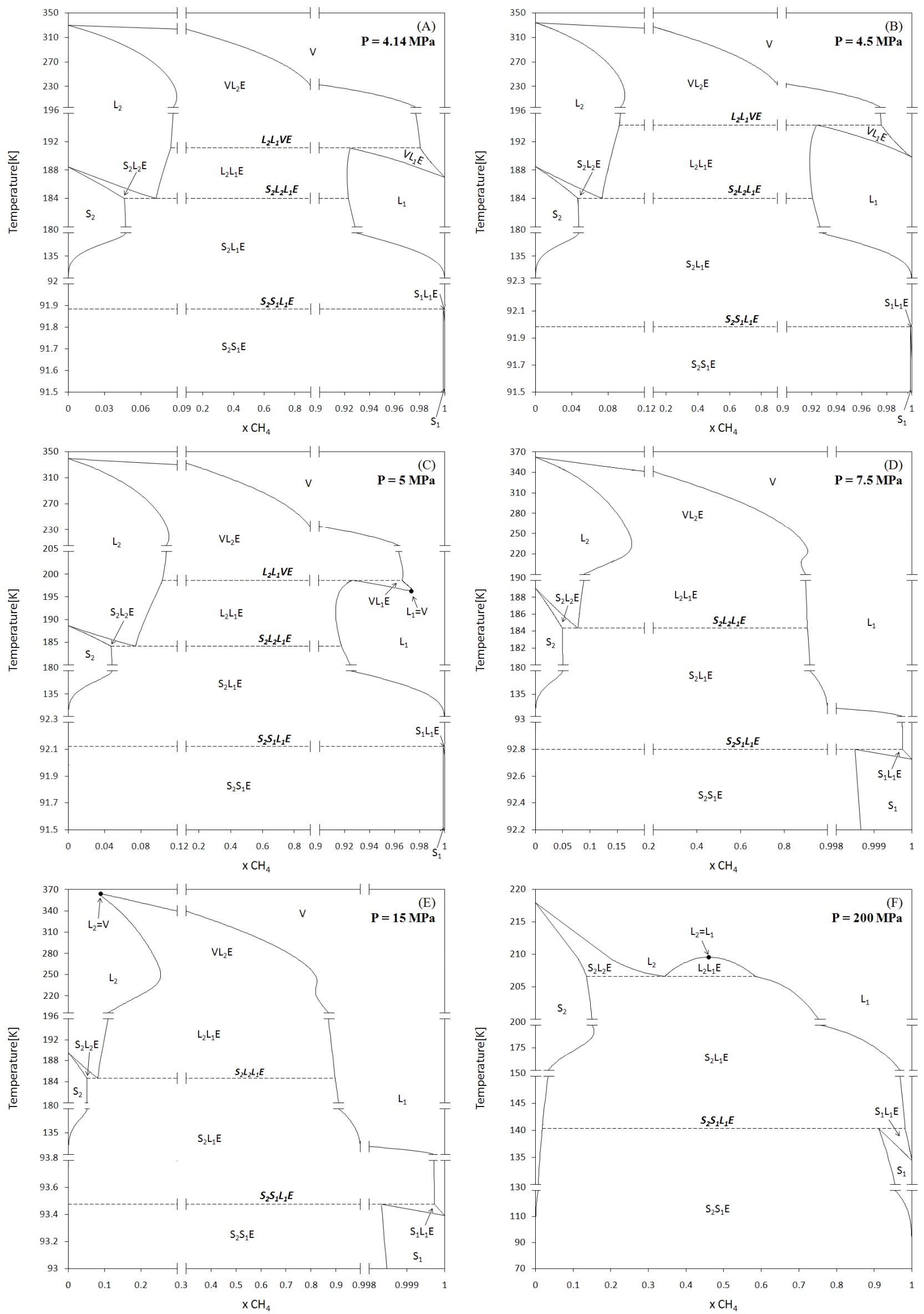

Figure 14. Calculated temperature-composition (Tx) cross sections for the regions 7P-12P. 


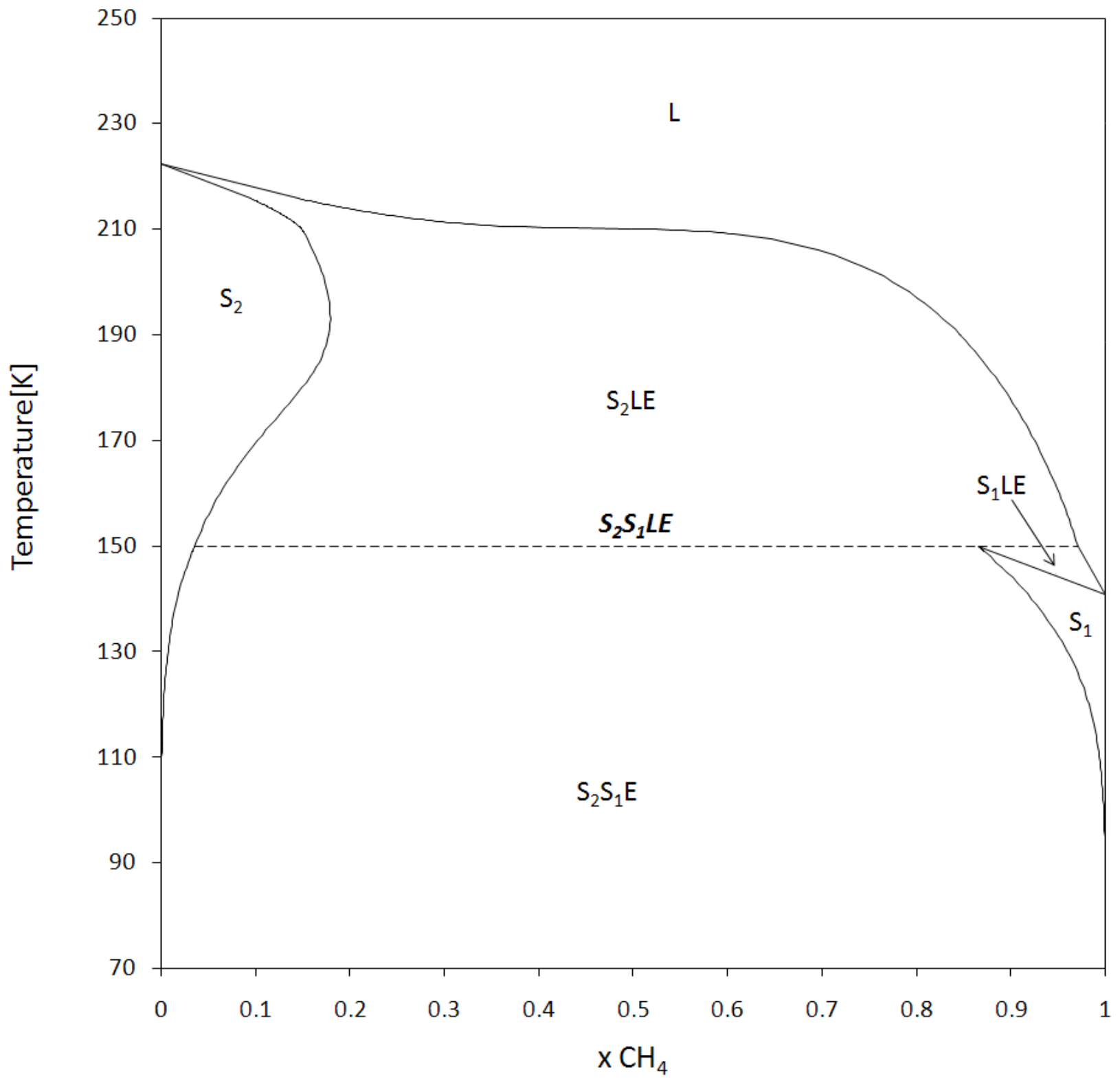

Figure 15. Calculated temperature-composition (Tx) cross sections at $235 \mathrm{MPa}$, i.e. the reference pressure for the region 13P.

\section{Miscibility of the Solid Phases and Allotropic Behavior of $\mathrm{H}_{2} \mathrm{~S}$}

The first comment concerning the Px and Tx cross sections calculated by the SLV EoS concerns the purity of the solid phases $S_{1}$ and $S_{2}$. As stated in Section 3, using the mixing rules developed for fluid phases presented in Eqs. 5-8 results in obtaining not pure solid phases, as it can be observed for instance in Figure 15. The Tx cross section at $235 \mathrm{MPa}$ presents a solid phase $\mathrm{S}_{2}$ rich in $\mathrm{H}_{2} \mathrm{~S}$ with a maximum mole fraction of methane of 0.18 , and a solid phase $\mathrm{S}_{1}$ rich in $\mathrm{CH}_{4}$ where the mole fraction of hydrogen sulfide reaches a maximum of 0.13 . As already stated, any evidence has been 
provided yet in the literature concerning the purity of the solid phases in the methane + hydrogen sulfide system, and the results here presented resulted from the mere application of the cited mixing rules in the SLV EoS.

Moreover, as previously introduced in this section, also the position of the $\mathrm{S}_{2} \mathrm{~S}_{1} \mathrm{~L}_{1} \mathrm{VE}\left(\mathrm{QP}_{2}\right)$ has not been determined yet. The kind of the solid-liquid equilibrium of the system of interest strictly depends on the exact position of the quadruple point, $\mathrm{QP}_{2}$. The binary mixture of $\mathrm{CH}_{4}$ and $\mathrm{H}_{2} \mathrm{~S}$ presents immiscibility in the solid phase, but this feature could result in a solid-liquid equilibrium either of the eutectic type or the peritectic type. The discerning aspect is comparison between the mole fraction for instance of $\mathrm{CH}_{4}$ in the liquid phase $\mathrm{L}_{1}\left(\mathrm{xL}_{1}\right)$ and those in the solid phases $\mathrm{S}_{1}$ and $\mathrm{S}_{2}\left(\mathrm{xS}_{1}\right.$ and $\left.x \mathrm{~S}_{2}\right): \mathrm{xL}_{1}$ is lower than $\mathrm{xS}_{1}$ but higher than $\mathrm{xS}_{2}$ in the eutectic behavior, it is higher than both $\mathrm{xS}_{1}$ and $\mathrm{x} \mathrm{S}_{2}$ in the peritectic behavior.

According to the results presented in Figures 10C, 14C-14F, and 15, it clearly appears that the mole fraction of $\mathrm{CH}_{4}$ in the liquid phase $\mathrm{L}_{1}$ is higher than the mole fractions in the solid phases $\mathrm{S}_{1}$ and $\mathrm{S}_{2}$. This is a direct consequence of the position of the singular point $\mathrm{QP}_{2}$ in the PT diagram. No binary interaction parameter has been regressed in order to match an eutectic behavior seeing that there is no literature evidence of this feature for the $\mathrm{CH}_{4}+\mathrm{H}_{2} \mathrm{~S}$ system.

The last analysis concerning the results of the SLV EoS is related to the three different crystal structures of $\mathrm{H}_{2} \mathrm{~S}$ that should be considered for obtaining the real behavior of the system. As introduced in Section 2, $\mathrm{H}_{2} \mathrm{~S}$ presents a triple point of solid $_{\gamma}$-solid ${ }_{\beta}$-vapor equilibrium at $103.5 \mathrm{~K}$ and triple point of $\operatorname{solid}_{\beta}$-solid ${ }_{\alpha}$-vapor equilibrium at $126 \mathrm{~K}$ in addition to the common triple point of solid $_{\alpha}$-liquid-vapor at $187.7 \mathrm{~K} .^{42}$ The triple points at low temperature are stated to occur at the zeropressure limit, while the solid-liquid-vapor equilibrium is at $22.3 \mathrm{kPa}^{45}$

Being the SLV EoS in Eq. 1 a fourth-degree polynomial in the variable volume, a single root can be associated to the solid volume, being the other roots related to the fluid phases. In dealing with mixtures, this solid volume correspond to a solid phase rich in either $\mathrm{H}_{2} \mathrm{~S}$ or $\mathrm{CH}_{4}$, which explains 
the possibility of representing the phases $S_{2}$ and $S_{1}$. To the contrary, the possibility of representing several solid phases for each pure component is outside the range of applicability of this EoS.

Nevertheless, the way the pure $\mathrm{H}_{2} \mathrm{~S}$ solid phases $\gamma$ and $\beta$ affect the phase equilibrium behavior of the mixture can be added relatively easily in both Tx and Px cross sections. For instance, Figures $16 \mathrm{~A}$ and $16 \mathrm{~B}$ present the Tx cross sections at $4.14 \mathrm{MPa}$ in the range $91.8 \mathrm{~K}-196 \mathrm{~K}$ considering a single phase for the solid $\mathrm{H}_{2} \mathrm{~S}, \mathrm{~S}_{2}$, and two additional solid-solid transitions occurring in pure $\mathrm{H}_{2} \mathrm{~S}$ at 103.5 K and $126 \mathrm{~K}$, respectively.

One can notice at once that the phase $S_{\alpha}$ in Figure 16B takes the role of the phase $S_{2}$ in Figure 16A. In addition to that, the $S_{2} S_{1} L_{1} E$ is replaced by the $S_{\gamma} S_{1} L_{1} E$ at about $91.9 \mathrm{~K}$, while two new threephase equilibria appear. $A S_{\gamma} S_{\beta} E$ originating at $103.5 \mathrm{~K}$ ends at the temperature of the former, the $\mathrm{S}_{\gamma} \mathrm{S}_{\beta} \mathrm{L}_{1} \mathrm{E}$ at about $92 \mathrm{~K}$, and a $\mathrm{S}_{\beta} \mathrm{S}_{\alpha} \mathrm{E}$ originating at $126 \mathrm{~K}$ ends at the temperature of the latter, namely the $S_{\beta} S_{\alpha} L_{1} E$ placed at about $108 \mathrm{~K}$. The temperatures of these $S_{S L_{1}} E$ have been randomly fixed and supposed lower than the correspondent solid-solid transitions of pure $\mathrm{H}_{2} \mathrm{~S}$.

As it is possible to observe in Figure 16, the inclusion of different crystal structures of $\mathrm{H}_{2} \mathrm{~S}$ does not modify the solid-fluid equilibria, although the different solid phases imply the presence of supplementary solid-solid and solid-solid-fluid equilibria.
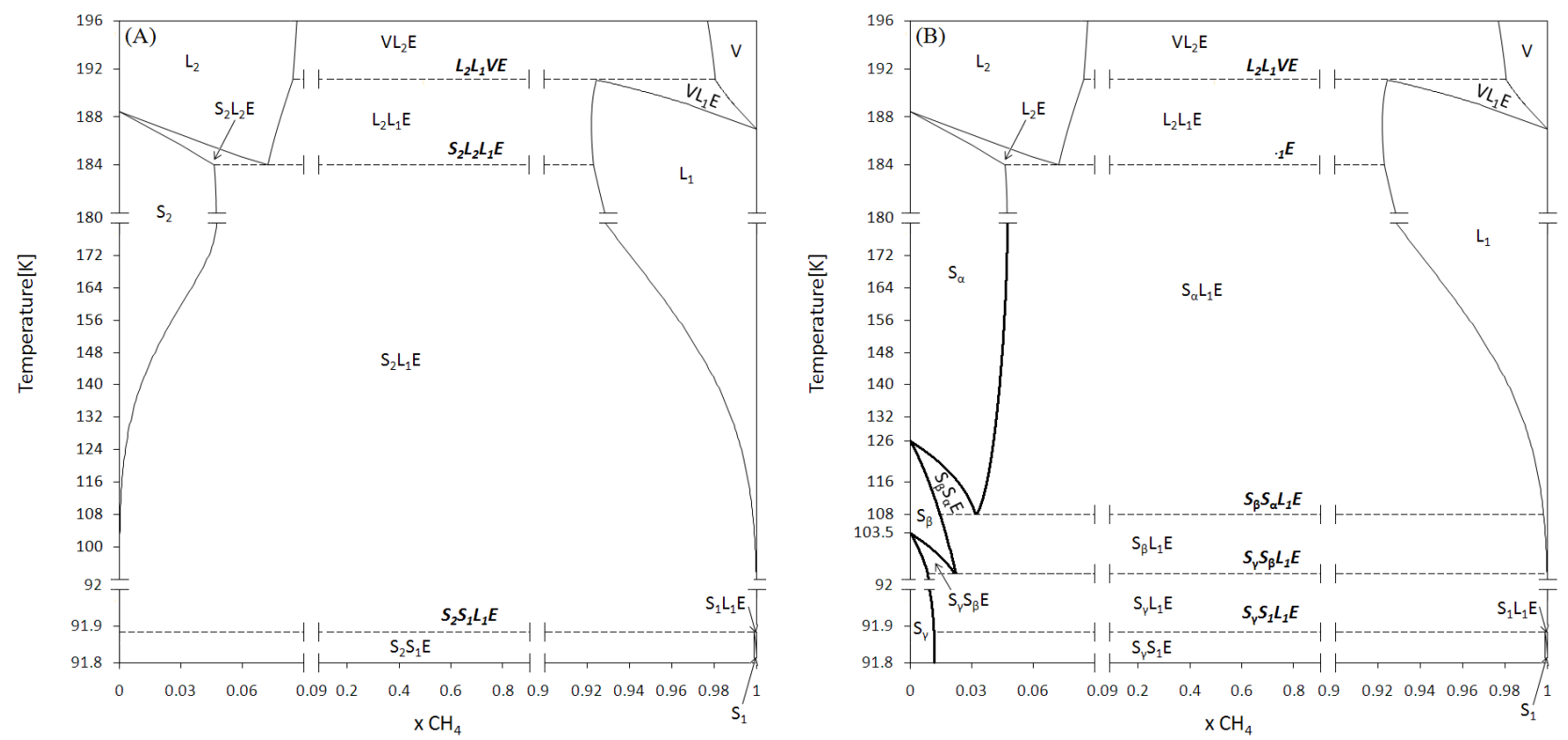

Figure 16. Comparison between the Tx cross sections at 4.14 MPa without (A) and with (B) the solid $\alpha^{-}$ solid $_{\beta}$ and solid ${ }_{\beta}$-solid ${ }_{\gamma}$ transitions of $\mathrm{H}_{2} \mathrm{~S}$. 


\section{Conclusions}

The increasing global energy demand and the availability of highly sour natural gas reserves establish the need of a detailed description of the phase behavior of systems containing methane and hydrogen sulfide in order to properly tune thermodynamic models and, most of all, to perform the correct process design of new gas purification technologies (particularly the low temperature ones) that are required to allow the commercialization of such a kind of low quality natural gas reserves. Different authors studied the phase behavior of the system methane - hydrogen sulfide considering only fluid phases, whereas few works considered the presence of a pure solid phase of $\mathrm{H}_{2} \mathrm{~S}$. The experimental works proposed in the last 60 years investigated the phase behavior of the system in a large proportion of the Pressure-Temperature (PT) diagram down to about $180 \mathrm{~K}$. In particular, the work by Kohn and Kurata presented qualitative representations of the PT diagram and highlighted the complexity of the phase equilibrium behavior.

Nevertheless, no work has been proposed to reproduce the PT diagram of the mixture down to the triple point of methane by means of a unified thermodynamic model for both fluid and solid phases. In addition to that, literature data never exceed $14 \mathrm{MPa}$.

In this work, the complete PT diagram of the methane - hydrogen sulfide system has been investigated down $70 \mathrm{~K}$ and for pressures up to $250 \mathrm{MPa}$ thanks to a model based on the analytic Solid-Liquid-Vapor Equation of State (SLV EoS) proposed in 2003 by Yokozeki. The parameters within the model have been tuned and validated against the available experimental data.

The calculated PT diagram and isobaric/isothermal cross sections show the complexity of the phase equilibrium behavior; immiscibility in both the liquid and solid phases characterizes the system and results in the presence of two quadruple points and two upper critical endpoints.

In addition to that, this works aims at proposing a map of the phase equilibrium behavior thus providing a rapid access to the evaluation of the change of the equilibria as function of pressure and temperature. 13 regions of both pressure and temperature have been found to resume all the possible 
schemes of the equilibrium behavior that can be encountered in dealing with the process simulation and/or plant design.

One of the strength of the model here applied is the possibility of representing the rather complex phase equilibrium behavior of the system by means of a single binary interaction parameter. This point better highlights also the simplicity of the approach, enforcing the validity and the effective industrial interest of a simple thermodynamic tool, reliable in a wide region of possible operating conditions.

According to model results for the phase behavior of the system $\mathrm{CH}_{4}-\mathrm{H}_{2} \mathrm{~S}$, it is possible to identify areas where further experimental investigations are needed. A region of interest extends from temperatures below the UCEP1 and pressures up to $15 \mathrm{MPa}$. These experimental studies will be useful to better investigate the $\mathrm{L}_{2} \mathrm{VE}, \mathrm{L}_{1} \mathrm{VE}, \mathrm{L}_{1} \mathrm{~L}_{2} \mathrm{E}, \mathrm{S}_{2} \mathrm{~L}_{2} \mathrm{E}, \mathrm{S}_{2} \mathrm{~L}_{1} \mathrm{E}$ and $\mathrm{S}_{2} \mathrm{VE}$ regions where complete datasets (T, P and fluid phase compositions) are missing and phase behavior is complex. Particularly, it can be of interest to determine experimentally the existence of the narrow $\mathrm{L}_{2}$ area present at temperatures between the $\mathrm{QP}_{1}$ and the triple point of pure $\mathrm{H}_{2} \mathrm{~S}$. $\mathrm{TPx}_{2} \mathrm{x}_{1} \mathrm{y}$ data along the $\mathrm{L}_{1} \mathrm{~L}_{2} \mathrm{VE}$ locus, TPxy data along the $\mathrm{S}_{2} \mathrm{~L}_{2} \mathrm{VE}$ and $\mathrm{S}_{2} \mathrm{~L}_{1} \mathrm{VE}$ loci and $\mathrm{TPx}_{2} \mathrm{X}_{1}$ data along the $\mathrm{S}_{2} \mathrm{~L}_{2} \mathrm{~L}_{1} \mathrm{E}$ locus are also of paramount importance. These experimental data will provide useful information also for the validation and proper design of low-temperature process technologies for the purification of highly acid and/or sour natural gases and biogas.

\section{Nomenclature}

List of symbols

a Equation of state parameter

$a_{0} \quad$ Parameter in Eq. 2

$a_{1} \quad$ Parameter in Eq. 2

$a_{2} \quad$ Parameter in Eq. 2

b Solid covolume 
$b_{0} \quad$ Parameter in Eq. 3

$b_{1} \quad$ Parameter in Eq. 3

$b_{2} \quad$ Parameter in Eq. 3

c Liquid covolume

$d \quad$ Equation of state parameter

$k \quad$ Binary interaction parameter

$N \quad$ Number of points (experimental or auxiliary)

$N C \quad$ Number of components in the mixture

$P \quad$ Pressure

$R \quad$ Gas constant

$T \quad$ Temperature

v Molar volume

$x \quad$ Mole fraction

Z Compressibility factor

\section{Subscript}

c Critical point property

$i \quad$ Relative to the substance $i$

$j \quad$ Relative to the substance $j$

$i j \quad$ Relative to the interaction between substance $i$ and the substance $j$

$r \quad$ Reduced property

$t \quad$ Triple point property

1 Relative to methane

2 Relative to hydrogen sulfide

Superscript

calc Calculated value

exp Experimental value 
$m \quad$ Parameter in Eq. 3

$n \quad$ Parameter in Eq. 2

Acronyms

AAD Average Absolute Deviation

EoS Equation of State

L Liquid phase

LLE Liquid - Liquid Equilibrium

LLVE Liquid - Liquid - Vapor Equilibrium

MAD Maximum Absolute Deviation

QP Quadruple Point

S Solid phase

SLE Solid - Liquid Equilibrium

SLL Solid - Liquid - Liquid Equilibrium

SLVE Solid - Liquid - Vapor Equilibrium

SSE Solid - Solid Equilibrium

SSLE Solid - Solid - Liquid Equilibrium

SSVE Solid - Solid - Vapor Equilibrium

SVE Solid - Vapor Equilibrium

V Vapor phase

VLE Vapor - Liquid Equilibrium

UCEP Upper Critical EndPoint

\section{Literature Cited}

1. British Petroleum Energy Outlook 2035, www.bp.com (accessed May 2014).

2. Carrol J, Foster J. New Challenges \& Solutions in Designing Large Sour Gas Projects 2008. www.fwc.com (accessed May 2014). 
3. Burgers WJF, Northrop PS, Kheshgi HS, Valencia JA. Worldwide development potential for sour gas. Energy Procedia. 2011;4:2178-2184.

4. Rojey A, Jaffaret C, Cornot-Gandolphe S, Durand B, Jullian S, Valais M. Natural Gas Production Processing Transport. Paris: Editions Technip, 1994.

5. Haut RC, Denton RD, Thomas ER. Development and application of the Controlled-Freeze-Zone Process. SPE Prod Eng. 1989;4:265-271.

6. Parker ME, Northrop S, Valencia JA, Foglesong RE, Duncan WT. $\mathrm{CO}_{2}$ management at ExxonMobil's LaBarge field, Wyoming, USA. Energy Procedia. 2011;4:5455-5470.

7. Northrop SP, Valencia JA. The CFZTM process: A cryogenic method for handling high- $\mathrm{CO}_{2}$ and $\mathrm{H}_{2} \mathrm{~S}$ gas reserves and facilitating geosequestration of $\mathrm{CO}_{2}$ and acid gases. Energy Procedia. 2009;1:171-5470.

8. Valencia JA, Denton RD. Method and apparatus for separating carbon dioxide and other acid gases from methane by the use of distillation and a controlled freeze zone. U.S. Patent 4533372 , August 6, 1985.

9. Valencia JA, Victory DJ. Method and apparatus for cryogenic separation of carbon dioxide and other acid gases from methane. U.S. Patent 4923493, May 8, 1990.

10. Valencia JA, Victory DJ. Bubble cap tray for melting solids and method for using same. U.S. Patent 5265428, November 30, 1993.

11. Holmes AS, Price BC, Ryan JM, Styring RE. Pilot tests prove out cryogenic acid-gas/hydrocarbon separation processes. Oil Gas J. 1983;81(26):85-86.

12. Holmes AS, Ryan JM. Cryogenic distillative separation of acid gases from methane. U.S. Patent 4318723, March 9, 1982.

13. Holmes AS, Ryan JM. Distillative separation of carbon dioxide from light hydrocarbons. U.S. Patent 4350511, September 21, 1982.

14. Pellegrini LA, Process for the removal of $\mathrm{CO}_{2}$ from acid gas. W.O. Patent 2014/054945A2, April 10, 2014. 
15. Langé S, Pellegrini LA, Vergani P, Lo Savio M. Energy and economic analysis of a new lowtemperature distillation process for the upgrading of high- $\mathrm{CO}_{2}$ content natural gas streams. Ind Eng Chem Res. 2015;54(40):9770-9782.

16. Hart A, Gnanendran N. Cryogenic $\mathrm{CO}_{2}$ capture in natural gas. Energy Procedia. 2009;1:697-706.

17. Lallemand F, Lecomte F, Streicher C. Highly sour gas processing: $\mathrm{H}_{2} \mathrm{~S}$ bulk removal with the Sprex process. International Petroleum Technology Conference, Doha, Qatar, Nov 21-23, 2005.

18. Lallemand F, Perdu G, Normand L, Weiss C, Magne-Drisch J, Gonnard S. www.digitalrefining.com/article/1000937 (accessed September 2014).

19. Schinkelshoek P, Epsom HD. Supersonic gas conditioning - commercialization of Twister ${ }^{\mathrm{TM}}$ technology. 87th GPA Annual Convention, Grapevine, Texas, USA, March 2-5, 2008.

20. Rufford TE, Smart S, Watson GCY, Graham BF, Boxall J, Dinizda Costa JC, Maya EF. The removal of $\mathrm{CO}_{2}$ and $\mathrm{N}_{2}$ from natural gas: a review of conventional and emerging process technologies. J Petrol Sci Eng. 2012;94-95:123-154.

21. Valencia JA, Kelman SD, Nagavarapu AK, Maher DW. The Controlled Freeze Zone Technology for the Commercialization of Sour Gas Resources. International Petroleum Technology Conference, Doha, Qatar, Jan 19-22, 2014.

22. Reamer HH, Sage BH, Lacey WN. Phase equilibria in hydrocarbon systems: volumetric and phase behavior of the methane-hydrogen sulfide. Ind Eng Chem. 1951;43(4):976-981.

23. Robinson DB, Bailey JA. The carbon dioxide-hydrogen sulphide-Methane System, Part 1: phase behavior at $100^{\circ} \mathrm{F}$. Can J Chem Eng. 1957;35:151-158.

24. Robinson DB, Lorenzo AP, Macrygeorgos CA. The carbon dioxide-hydrogen sulphide-Methane System, Part 2: phase behavior at $40^{\circ} \mathrm{F}$ and $60^{\circ} \mathrm{F}$. Can J Chem Eng. 1959;37:212-217.

25. Kohn JP, Kurata F. Heterogeneous phase equilibria of the methane-hydrogen sulfide system. AIChE J. 1958;4(2):211-217. 
26. Van Konynenburg PH, Scott RL. Critical lines and phase equilibria in binary van der Waals mixtures. Phil Trans $R$ Soc Lond. 1980;298:495-540.

27. Bolz A, Deiters UK, Peters CJ, De Loos TW. Nomenclature for phase diagrams with particular reference to vapor-liquid and liquid-liquid equilibria. Pure Appl. Chem. 1998;70:2233-2257.

28. Cheung H, Zander EH. Solubility of carbon dioxide and hydrogen sulfide in liquid hydrocarbons at cryogenic temperatures. Chem Eng Progress Symp Series 88. 1968;64:34-43.

29. Yarim-Agaev NL, Afanasenko LD, Matrienko VG, Ryabkin YY, Tolmacheva GB. Gas-liquid equilibrium in the methane-hydrogen sulfide system below 273 K. Ukr Khim Zh. 1991;57:701-704.

30. Coquelet C, Valtz A, Stringari P, Popovic M, Richon D, Mougin P. Phase equilibrium data for the hydrogen sulphide + methane system at temperatures from 186 to $313 \mathrm{~K}$ and pressures up to about 14 MPa. Fluid Phase Equilib. 2014;383:94-99.

31. Huron MJ, Dufour GN, Vidal J. Vapour-liquid equilibrium and critical locus curve calculations with the Soave equation for hydrocarbon systems with carbon dioxide and hydrogen sulphide. Fluid Phase Equilib. 1977-1978;1:247-265.

32. Adachi Y, Lu BCY, Sugie H. A four-parameter equation of state. Fluid Phase Equilib. $1983 ; 11: 29-48$.

33. Mohsen-Nia M, Moddaress H, Mansoori GA. Sour natural gas and liquid equation of state. $J$ Petrol Sci Eng. 1994;12:127-136.

34. Sakoda N, Uematsu M. Thermodynamic properties of the binary mixture of methane and hydrogen sulfide. Z Phys Chem. 2005;219(9):1299-1319.

35. Sakoda N, Uematsu M. A thermodynamic property model for the binary mixture of methane and hydrogen sulfide. Int J Thermophysics. 2005;26(5):1303-1325.

36. Privat R, Mutelet F, Jaubert JN. Addition of the hydrogen sulfide group to the PPR78 model (Predictive 1978, Peng Robinson EoS with temperature dependent $\mathrm{k}_{\mathrm{ij}}$ calculated through a group contribution method). Ind Eng Chem Res. 2008;47(24):10041-10052. 
37. Tsivitzelis I, Kontogeorgis GM, Michelsen ML, Stenby EH. Modeling phase equilibria for acid gas mixtures using the CPA equation of state. I. Mixtures with $\mathrm{H}_{2} \mathrm{~S}$. AIChE J. 2010;56(11):2965-2982.

38. Tang X, Gross J. Modeling the phase equilibria of hydrogen sulfide and carbon dioxide in mixture with hydrocarbons and water using the PCP-SAFT equation of state. Fluid Phase Equilib., 2010;293:11-21.

39. Yokozeki A. Analytical equation of state for solid-liquid-vapor phases. Int J Thermophys. 2003;24(3):568-619.

40. Colwell JH, Gill EK, Morrison JA. Thermodynamic properties of $\mathrm{CH}_{4}$ and $\mathrm{CD}_{4}$. Interpretation of the properties of the solids. J Chem Phys. 1963;39:635-653.

41. Stevenson R. Solid methane-changes in phase under pressure. J Chem Phys. 1957;27:656-658.

42. Giauque WF, Blue RW. Hydrogen sulfide. The heat capacity and vapor pressure of solid and liquid. The heat of vaporization. A comparison of thermodynamic and spectroscopic values of the entropy. J Am Chem Soc. 1936;58:831-837.

43. Stevenson R. Tentative phase diagram of solid $\mathrm{H}_{2}$ S. J Chem Phys. 1957;27:147-150.

44. Stringari P, Campestrini M, Coquelet C, Arpentinier P. An equation of state for solid-liquidvapor equilibrium applied to gas processing and natural gas liquefaction. Fluid Phase Equilib. $2014 ; 362: 258-267$.

45. Huber ML, McLinden MO, Lemmon EW. NIST Standard Reference Database23, Reference Fluid Thermodynamic and Transport Properties-REFPROP, Version 8.0, National Institute of Standards and Technology, Standard Reference Data Program, Gaithersburg, 2007.

46. Clark AM, Cockett, AH, Eisner HS. The vapour pressure of hydrogen sulphide. Proc Roy Soc London Ser A. 1951;209:408-415.

47. Prausnitz JP, Lichtenthaler RN, de Azevedo EG. Molecular thermodynamics of fluid-phase equilibria (2nd edition). New Jersey: Prentice-Hall, Englewood Cliffs, 1986.

48. Air Liquide, Encyclopédie des Gaz, ELSEVIER, 1976. 
49. Cotton S. Hydrogen sulfide. Uppingham School, Rutland, UK. www.chm.bris.ac.uk/motm/H2S/h2sjm.htm (accessed May 2015). 